\title{
Self-assembled monolayers and titanium dioxide: From surface patterning to potential applications
}

Yaron Paz

\section{Review}

\section{Address:}

The Department of Chemical Engineering, The Russell-Berrie Institute of Nanotechnology and The Grand Water Research Institute,

Technion, Haifa 32000, Israel

Email:

Yaron Paz - paz@tx.technion.ac.il

Keywords:

photocatalysis; remote degradation; self-assembled monolayers; titanium dioxide
Beilstein J. Nanotechnol. 2011, 2, 845-861.

doi:10.3762/bjnano.2.94

Received: 18 October 2011

Accepted: 06 December 2011

Published: 20 December 2011

This article is part of the Thematic Series "Self-assembly at solid surfaces".

Guest Editors: S. R. Cohen and J. Sagiv

(C) 2011 Paz; licensee Beilstein-Institut.

License and terms: see end of document.

\begin{abstract}
The ability to control the properties of self-assembled monolayers (SAMs) attached to solid surfaces and the rare photocatalytic properties of titanium dioxide provide a rationale for the study of systems comprising both. Such systems can be realized in the form of $\mathrm{SAMs}$ grown on $\mathrm{TiO}_{2}$ or, in a complementary manner, as $\mathrm{TiO}_{2}$ grown on $\mathrm{SAMs}$. Accordingly, the current status of knowledge regarding SAMs on $\mathrm{TiO}_{2}$ is described. Photocatalytic phenomena that are of specific relevance to SAMs, such as remote degradation, and cases where SAMs were used to study photocatalytic phenomena, are discussed as well. Mastering of micropatterning is a key issue en route to a successful assimilation of a variety of titanium dioxide based devices. Accordingly, particular attention is given to the description of a variety of methods and techniques aimed at utilizing the photocatalytic properties of titanium dioxide for patterning. Reports on a variety of applications are discussed. These examples, representing the areas of photovoltaics, microelectronics, microelectromechanics, photocatalysis, corrosion prevention and even biomedicine should be regarded as appetizers paving the way for further studies to be performed.
\end{abstract}

\section{Introduction}

Photocatalytic degradation of pollutants is attracting increasing attention. In this context, anatase-phase titanium dioxide is regarded as the photocatalyst of choice, due to its low cost, nontoxicity, and relatively high efficiency, which make it suitable not only for air and water decontamination [1,2] but also for self-cleaning applications [3]. The general scheme for the photocatalytic destruction of organics involves the excitation of this semiconductor by irradiation with suprabandgap photons and migration of the electron-hole pairs to the surface of the photocatalyst, where the holes are trapped by $\mathrm{H}_{2} \mathrm{O}$ or $\mathrm{OH}^{-}$ adsorbed at the surface, thus forming hydroxyl radicals. In parallel, the electrons reduce adsorbed oxygen [4] to form superoxide radicals. The first step in the photocatalytic degradation of most organic compounds is an oxidative attack by the hydroxyl radicals, which eventually, following secondary reactions, gives stable molecules such as $\mathrm{CO}_{2}$ and water $[5,6]$. 
Nevertheless, it was shown that some halo-organics $[7,8]$ and highly toxic heavy-metal ions such as $\mathrm{Cr}(\mathrm{VI})[9,10]$ could be degraded reductively by photoinduced electrons. Langmuir-Hinshelwood type kinetics is often observed both in the liquid phase and in the gas phase, suggesting, albeit not proving $[11,12]$ the need for adsorption as a prerequisite for photocatalysis.

Self-assembled monolayers (SAMs) being chemisorbed in an ordered manner on surfaces such as metals $(\mathrm{Au}, \mathrm{Ag})$, oxides $\left(\mathrm{SiO}_{2}, \mathrm{Al}_{2} \mathrm{O}_{3}, \mathrm{TiO}_{2}\right)$ and semiconductors $(\mathrm{Si}, \mathrm{GaN}, \mathrm{InP}$ InGaAs) provide a unique way to alter the properties of a surface at will. This ability may be manifested through a variety of phenomena, among which are wetting phenomena (hydrophobicity, hydrophilicity and oleophobicity), electronic phenomena (from affecting band bending and work function, to charge conduction), and, no less important, the ability to form tailored three-dimensional supramolecular arrays by attaching a specific molecule or a particle to an external functional group.

Being adsorbed on the surface of titanium dioxide or in its vicinity, organic self-assembled monolayers may affect the photocatalytic properties of titania as well as be affected by these properties. Likewise, the superhydrophilicity of $\mathrm{TiO}_{2}$ known to be induced upon exposure to UV light [13] may affect the chemisorption process of SAMs. This gives rise to diverse phenomena, which can be utilized in many ways, from the study of fundamental issues in $\mathrm{TiO}_{2}$ photocatalysis to the growth of supramolecular structures; from serving as a tool for patterning to suggesting means to obtain the selective photocatalytic degradation of highly toxic contaminants. This potential for synergism between self-assembled monolayers and photocatalytic titanium dioxide is the subject of the following review, whose aim is to bring the prospects and obstacles of this combination to the attention of the scientific community. It should be noted that for obvious reasons this manuscript does not cover devices where the titanium dioxide serves to accept photoinduced electrons from sensitizers that cannot be strictly considered as SAMs, i.e., most types of dye-sensitized solar cells (DSSCs).

\section{Review}

\section{Self-assembled monolayers chemisorbed on $\mathrm{TiO}_{2}$}

Both $\mathrm{TiO}_{2}$ and $\mathrm{SiO}_{2}$ are oxides capable of forming surface hydroxyls, and therefore one could imagine that SAMs on titania may resemble SAMs on silica. This similarity is expected to be manifested primarily by the type of head groups that connect between the surface and the organic tails. Indeed, head groups such as chlorosilanes $\left(\mathrm{R}_{n} \mathrm{SiCl}_{4-n}\right.$ with $\left.n=1,2,3\right)$, alkoxysilanes $\left(\mathrm{R}_{n} \mathrm{Si}\left(\mathrm{OR}^{\prime}\right)_{4-n}\right.$ with $\left.n=1,2,3\right)$, carboxylic acids and isocyanates $(-\mathrm{N}=\mathrm{C}=\mathrm{O})$ are common on both substrates. The fact that the $\mathrm{Si}-\mathrm{O}$ bond length in silica $(1.5-1.7 \AA$ depending on the crystalline form) is similar to that of the $\mathrm{Ti}-\mathrm{O}$ bond length in titania (1.9 $\AA$ ) may suggest similar compactness. On the other hand, the difference between the electronegativity of Ti to that of Si, (1.54 and 1.90 by Pauling's scale, respectively) which affects the polarity of the $\mathrm{M}-\mathrm{O}$ bond of the oxide, the point of zero charge of the oxide, and the number of $\mathrm{OH}$ sites on the surface are expected to influence the tendency of these two oxides to form SAMs and the structure and stability of the formed SAMs.

Chlorosilanes and alkoxysilanes SAMs are characterized by hydrolysis-condensation reactions leading to the formation of $\mathrm{M}-\mathrm{O}-\mathrm{Si}$ bonds where $\mathrm{M}$ is in this context is $\mathrm{Si}$ or Ti. The chemical anchoring of the alkylsilanes to $\mathrm{TiO}_{2}$ is characterized by several changes in the FTIR spectrum, namely shifting of the $1091 \mathrm{~cm}^{-1}$ band found in neat $\mathrm{TiO}_{2}$ (bending vibration of $\mathrm{Ti}-\mathrm{OH}$ ) to lower wavenumbers (ca. $1000 \mathrm{~cm}^{-1}$ ) due to the formation of Ti-O-Si bonds, and the disappearance of the in-planebending vibration of surface $\mathrm{O}-\mathrm{H}$ at $1402 \mathrm{~cm}^{-1}$ [14].

Generally speaking, a comprehensive comparison between SAMs on silica and SAMs on titanium dioxide is somehow problematic as the latter were by far less-extensively studied than the former. It is commonly claimed that silanes capable of cross linking (i.e., having at least three leaving groups) grow by an islandlike growth mechanism, whereas SAMs that are not capable of cross linking grow by a uniform growth mechanism [15]. While this is well-established for SAMs on Si, results for organosilanes SAMs on titanium dioxide are much more ambiguous. The lower electronegativity of titanium suggests that the condensation reaction is faster than on $\mathrm{SiO}_{2}$, and as a consequence the grafting of octadecyl trichlorosilane (OTS) on $\mathrm{TiO}_{2}$ is faster [16]. To some extent this is related to the known ability of $\mathrm{Ti}(\mathrm{OR})_{4}$ to catalyze silanol condensation in $\mathrm{TiO}_{2}-\mathrm{SiO}_{2}$ sol-gel systems. Since island formation of OTS molecules requires lateral mobility, which may be hindered if the grafting is too strong, one may expect the OTS islands on $\mathrm{TiO}_{2}$ to be smaller than on $\mathrm{SiO}_{2}$.

There are several indications (most of them based on the FTIR signal of the $\mathrm{C}-\mathrm{H}$ stretch envelope) that the amount of chemisorbed trichlorosilane molecules is higher in $\mathrm{TiO}_{2}$ than in $\mathrm{SiO}_{2}$, possibly due to the presence of surplus water [17] or, in the case of $\mathrm{TiO}_{2}$ films consisting of sintered nanocrystalline $\mathrm{TiO}_{2}$, due to a difference between the geometrical area and the true area [18]. Conversely, the density of a protein, immobilized on a substrate through an alkylsilane SAM having a terminal amine, was observed to be lower on a $\mathrm{TiO}_{2}$ substrate than on $\mathrm{SiO}_{2}$ substrate [19]. Here, it was claimed by the authors that the more ionic character of the Ti-O bond may 
require higher energies to form Ti-OH groups, leading to lower density of surface hydroxyls unless an extended exposure to $\mathrm{O}_{2}$ plasma in the presence of water vapor is performed.

The formation of OTS monolayers on titanium dioxide was studied in structures consisting of well-defined microdomains of $\mathrm{TiO}_{2}$ and noble metals such as gold and platinum. It was found that monolayers chemisorbed in the presence of the metallic micro-islands were denser than monolayers chemisorbed on $\mathrm{TiO}_{2}$ substrates that had no metallic islands. Results were explained in terms of charging effects [18]. That charging of the substrate may affect the chemisorption of organosiloxane monolayers can be deduced also from a comparison between $\mathrm{SAMs}$ on $\mathrm{SiO}_{2}$, on mica and on mica coated with ultrathin layers of $\mathrm{SiO}_{2}$. Here, it was found that the adsorption rate decreased with the width of the silica overlayer, and this result was explained by the increased shadowing of an electrostatic interaction between the negatively charged mica surface and the polar head group of the adsorbed molecules [20].

The effect of raising the temperature may be manifested in SAMs through disordering (formation of "kink" configurations), detachment of the molecules, or burning. FTIR studies of temperature effects on a variety of organosilane SAMs on $\mathrm{TiO}_{2}$ found that all the organosilane SAMs exhibited good thermal and oxidative stability, with no mass loss below $200{ }^{\circ} \mathrm{C}$ [15], as is known also for organosilanes on silicon [21] A different study on in-air pyrolization of thioacetate-terminated (trichlorosilyl) hexadecane on $\mathrm{SiO}_{2}$ and $\mathrm{TiO}_{2}$ did not reveal any substrate effect on the onset of burning and on the temperature dependence of the process [22].

Data on contact-angle comparisons between organosilanes on silica and on titania is quite scarce. In this respect, contact-angle measurements of CVD-made tetrafunctional cyclic siloxane monolayers $(1,3,5,7$-tetramethylcyclotetrasiloxane $\left.\left(\mathrm{C}_{4} \mathrm{H}_{16} \mathrm{O}_{4} \mathrm{Si}_{4}\right)\right)$ did not reveal much of a difference between SAMs on oxidized titanium versus SAMs on oxidized aluminum [23]. In both cases, the water contact angle was found to be $103^{\circ}$ when the CVD process took place at $80{ }^{\circ} \mathrm{C}$, and $163^{\circ}$ when the process took place at $180^{\circ} \mathrm{C}$. The $n$-hexadecane contact angles were also the same for both substrates, i.e., $32^{\circ}$ and $0^{\circ}$ for monolayers grown at $80^{\circ} \mathrm{C}$ and $180^{\circ} \mathrm{C}$, respectively. The fact that the contact angles on these very short SAMs $(0.5 \mathrm{~nm}$ in thickness) revealed a lack of sensitivity to the type of substrate suggests (albeit not proves) that a similar situation may prevail also with SAMs having long alkyl chains, whose outer groups are located far from the substrate and in which multiple intermolecular van-der-Waals (VdW) interactions play a larger role.
The high solubility of polysiloxanes in $\mathrm{CO}_{2}$ led researchers to study the silanization of titanium dioxide under supercritical conditions. It was found that despite a tendency to form a disordered, three-dimensional silanized structure [24], a monolayer with a very low degree of vertical polycondensation can be obtained at pressures above 10.0-12.5 MPa [25]. Such monolayers have a relatively lower grafting density with respect to chemisorption by conventional methods (2.8-3.0 molecules per $\mathrm{nm}^{2}$ versus $4.3-4.8$ molecules per $\mathrm{nm}^{2}$ ).

It is worth mentioning that a study on organosilane monolayers formed on the surfaces of zirconia and titania (anatase and rutile), by a gas-phase process employing organosilicon hydrides, found that the effect of the underlying substrate on the adsorption of nitrogen on the SAMs was insignificant [26]. Here, the heat of adsorption of the nitrogen molecules was found to increase as the grafting density of the SAMs was decreased from 4.23 groups $/ \mathrm{nm}^{2}$ for $\mathrm{C}_{18} \mathrm{H}_{37} \mathrm{SiH}_{3}$ to 2.75 groups $/ \mathrm{nm}^{2}$ for $\mathrm{H}_{3} \mathrm{Si}\left(\mathrm{CH}_{2}\right)_{8} \mathrm{SiH}_{3}$.

Unlike organosilane SAMs, whose tendency to form on $\mathrm{TiO}_{2}$ and $\mathrm{SiO}_{2}$ is quite similar, SAMs having phosphonic acid as their connecting head group are not formed on silicon dioxide but are formed easily from aqueous solutions on $\mathrm{TiO}_{2}, \mathrm{Al}_{2} \mathrm{O}_{3}$, $\mathrm{Ta}_{2} \mathrm{O}_{5}$ and $\mathrm{Nb}_{2} \mathrm{O}_{5}$ [27].

FTIR measurements of self-assembled alkanephosphate monolayers revealed a clear shift in the symmetric and antisymmetric methylene stretching bands toward lower wavenumbers with increasing adsorption time, indicating a change from a disordered conformation to a well-ordered structure [28]. The observation of a disorder-order change for alkanephosphate SAMs on $\mathrm{TiO}_{2}$ supported the validity of the uniform growth mechanism, i.e., strong chemisorption of single molecules that once chemisorbed are incapable of surface diffusion. The dichroic ratio of the methylene antisymmetric stretching band, defined as the intensity ratio of the band in the two polarizations $\left(A_{\mathrm{S}} / A_{\mathrm{p}}\right)$, was found to increase with adsorption time and to level off at a ratio of 1.3, further supporting the uniform growth mechanism. The results of the dichroic ratio for the well-packed monolayer were analyzed under the assumption of uniaxial orientation, yielding a tilt angle of the alkyl chains of $21^{\circ}$ relative to the surface normal. It should be noted that the uniform growth mechanism is considered to be typical for molecules that do not cross link ( $\mathrm{such}$ as $\mathrm{Si}\left(\mathrm{CH}_{3}\right)_{2}-\mathrm{Cl}$ for example) [15], hence it may imply that this was the case also with the alkanephosphates.

The binding of self-assembled monolayers of ${ }^{17} \mathrm{O}$-enriched phosphonic acids chemisorbed on titanium dioxide was studied by high-field NMR [29]. The presence of $\mathrm{P}-\mathrm{O}-\mathrm{Ti}, \mathrm{P}=\mathrm{O}$, and 
$\mathrm{P}-\mathrm{OH}$ indicated that mono-, bi- and tridentate surface phophonate units can be present in these monolayers (Figure 1). The relative contribution of each form was found to vary according to the tail group, namely the relative contribution of $\mathrm{P}-\mathrm{O}-\mathrm{Ti}, \mathrm{P}=\mathrm{O}$ and $\mathrm{P}-\mathrm{OH}$ was found to be different for $\mathrm{PhPO}_{3} \mathrm{H}_{2} / \mathrm{TiO}_{2}$ and $\mathrm{C}_{12} \mathrm{H}_{25} \mathrm{PO}_{3} \mathrm{H}_{2} / \mathrm{TiO}_{2}$. Unfortunately, the lack of uniqueness in the assignment of the relative contributions to the three forms of anchoring prevented calculation of the relative role of each type of anchoring. At any case, the chemical shift of the $\mathrm{P}-\mathrm{O}-\mathrm{Ti}$ sites was found to be consistent with bridging modes, negating the possibility of anchoring through chelating modes.

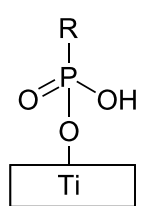

(1)

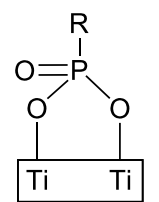

(2)

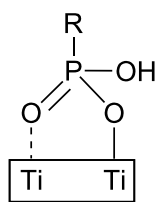

(3)

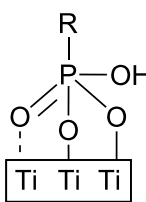

(4)

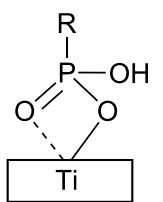

(5)
Figure 1: Schematic representation of binding modes between phosphonic acid SAMs and titanium dioxide (1) monodentate, (2) and (3) bridging bidentate, (4) bridging tridentate, (5) chelating bidentate (adapted from [29]).

A slightly different view of the binding between $n$-monoalkanephosphate $\mathrm{SAMs}$ and $\mathrm{TiO}_{2}$ was presented by Chen et al. who claimed, based on XPS measurements, that this type of SAM can be bonded to the $\mathrm{TiO}_{2}$ surface by way of both monodentate and bidentate coordination [30]. Accordingly, it was claimed that the monodentate and the bidentate of adjacent phosphate headgroups are linked by intermolecular hydrogen bonding.

An interesting phenomenon was found with SAMs connected to the $\mathrm{TiO}_{2}$ surface through a carboxylic acid group. Here, doping $\mathrm{TiO}_{2}$ nanoparticles with $\mathrm{Co}^{2+}$ at high concentrations (up to $23 \%$ ), where the $\mathrm{Co}^{2+}$ replaces $\mathrm{Ti}^{4+}$ by substitution, was found to significantly improve the solubility and dispersibility of the nanocrystals in aprotic solvents, upon coating with thin films of oleic acid $\left(\mathrm{CH}_{3}\left(\mathrm{CH}_{2}\right)_{7} \mathrm{CH}=\mathrm{CH}\left(\mathrm{CH}_{2}\right)_{7} \mathrm{COOH}\right)$ [31]. The aggregation on undoped particles was explained by the oleic acid forming a bilayer, with the carboxylic groups located at the solvent interface. In contrast, in doped particles, a monolayer exposing its hydrophobic functional groups to the aprotic solvents is formed, thus stabilizing the dispersion. This dependency in the formation of the thin layer on the doping was claimed to be related to the packing of the first layer. On doped nanoparticles the formed monolayer was denser than on undoped examples, thus preventing the interpenetration of hydrophobic chains that could have formed the bilayer structure.
Another functional headgroup used for the formation of SAMs on titanium dioxide is isocyanate $\left(\mathrm{CH}_{3}\left(\mathrm{CH}_{2}\right)_{n} \mathrm{~N}=\mathrm{C}=\mathrm{O}\right)$, which forms a relatively weak carbamate linkage with the surface [32]. Here, water contact-angle hysteresis for the SAM-covered $\mathrm{TiO}_{2}$ surfaces were found to be larger than that observed for the SAM-covered $\mathrm{SiO}_{2}$ surface, suggesting that alkyl isocyanate SAMs on $\mathrm{TiO}_{2}$ were more disordered and/or were less densely packed compared with alkyl isocyanate $\mathrm{SAMs}$ on $\mathrm{SiO}_{2}$. Similar to other SAMs on many substrates, the longer the alkyl chains were, the more stable were the SAMs, by virtue of a larger number of VdW interactions.

\section{$\mathrm{TiO}_{2}$ grown on SAMs}

There are quite a large number of manuscripts describing the growth of titanium dioxide on top of SAMs. The content of most of these publications is of little relevance to this minireview, since in most cases the photocatalytic properties of the grown $\mathrm{TiO}_{2}$ were not demonstrated. This lack of documented activity is at least partially related to the fact that in most cases the grown titanium dioxide was not in the photocatalytic anatase phase but rather it was amorphous. This amorphous phase can be transformed to anatase; however, it requires temperatures no less than $300{ }^{\circ} \mathrm{C}$, which are expected to severely damage the underlying organic SAM.

Generally speaking, there are three main methods for growing titanium dioxide particles and films on SAMs: Liquid-phase deposition (LPD), atomic-layer deposition, and sol-gel. Within the context of growing $\mathrm{TiO}_{2}$ on SAMs, the LPD method is probably the most popular. It employs a solution containing $\mathrm{TiF}_{6}{ }^{2-}$ anions together with boric acid. The fluoride ligand serves to slow down the hydrolysis of the titanium fluoride complex (Equation 1), enabling the deposition of the formed titanium dioxide on the SAMs, whereas the borate ions act to scavenge the fluoride ions formed during hydrolysis according to Equation 2.

$$
\begin{aligned}
& \mathrm{TiF}_{6}^{2-}+2 \mathrm{H}_{2} \mathrm{O} \rightarrow \mathrm{TiO}_{2}+4 \mathrm{H}^{+}+6 \mathrm{~F}^{-} \\
& \mathrm{BO}_{3}{ }^{3-}+4 \mathrm{~F}^{-}+6 \mathrm{H}^{+} \rightarrow \mathrm{BF}_{4}^{-}+3 \mathrm{H}_{2} \mathrm{O}
\end{aligned}
$$

As described below, the phase of the titanium dioxide obtained by this technique depends heavily on the substrate (namely the outer group of the SAM, the $\mathrm{pH}$ and the temperature).

Sulfonate $\left(-\mathrm{SO}_{3} \mathrm{H}\right)$-terminated $\mathrm{SAMs}$ can be used as substrates onto which nanoparticles and thin films of titanium dioxide can be deposited by an aqueous Ti(IV) route [33]. Here, the sulfonate group provides high local acidity and negative charge 
even at low $\mathrm{pH}$, thus promoting the hydrolysis and surface attachment of solvated titanium-containing species. It is noteworthy that the fast growth rate on sulfonic-terminated SAMs was also found when the titanium dioxide was grown from a solution containing titanium sulfate and hydrogen peroxide [34]. Obtaining SAMs with sulfonate outer groups is not trivial. It is usually done either by reacting chemisorbed SAMs having a thioacetate terminal group [33] or by reacting terminating thiol groups with $\mathrm{H}_{2} \mathrm{O}_{2}$ in acetic acid $[35,36]$.

By choosing sulfonate-terminated SAMs with long alkyl chains (or a sulfonate-capped polyelectrolyte multilayer) and by careful manipulation of the solution parameters, an anatase phase can be obtained with this method, without the need for high-temperature treatment. The same LPD conditions, but with a silicon substrate instead of a sulfonate-terminated SAM, yielded an amorphous film, demonstrating the importance of the substrate [37]. Low-temperature growth of anatase by LPD was also demonstrated with amine-terminated SAMs, taking advantage of the fact that at $\mathrm{pH} 2.8$, the substrate was charged positively, whereas the $\mathrm{TiO}_{2}$ precursor and the nucleated $\mathrm{TiO}_{2}$ were charged negatively, as confirmed by $\zeta$ potential measurements [38]. At the time, this route was considered to be of large importance for photocatalysis, since (in the case of the aqueous route) it provided a way to form the photoactive anatase phase at temperatures lower than $100{ }^{\circ} \mathrm{C}$, compared with $300-350{ }^{\circ} \mathrm{C}$ required in the sol-gel process, or with $170-240{ }^{\circ} \mathrm{C}$ required in the $\mathrm{TiCl}_{4}$ process performed under vacuum [39]. Meanwhile, other low-temperature processes for producing anatase, such as the titanyl sulfate route [40], have been developed.

Apart from the sulfonate terminated SAMs and the amineterminated SAMs, the LPD method was used also for the growth of titanium dioxide of unknown phase on SAMs (octadecyltrichlorosilane, phenyltrichlorosilane, vinyltrichlorosilane and $p$-tolyltrichlorosilane) that had been partially oxidized to yield $-\mathrm{OH}$ termination. The importance of this work was not in the growth itself, but rather in the fact that the underlying SAMs served as linkers to a polymeric substrate consisting of (aminopropyl)triethoxysilane grafted poly(ethylene terephthalate) [41].

The use of sol-gel methods, utilizing titanium alkoxides as $\mathrm{TiO}_{2}$ precursors in an alcoholic medium is a well-known technique for forming $\mathrm{TiO}_{2}$ (albeit not anatase) on solid substrates. The method was applied for the growth of titanium dioxide on $-\mathrm{CH}_{3}-[42,43],-\mathrm{OH}-[44]$, and - $\mathrm{COOH}$-terminated SAMs [45] In the last work the authors compared a two-steps method, in which a HS- $\left(\mathrm{CH}_{2}\right)_{10}-\mathrm{COOH}$ monolayer was first adsorbed on gold and then exposed to an ethanolic $\mathrm{TiO}_{2}$ colloid solution, and a one-step process in which an ethanolic colloid of $\mathrm{TiO}_{2}$ nanocrystallites was prepared by the sol-gel method in the presence of the functionalized thiols prior to adsorption onto the gold surface. It was found that the one-step process yielded a lower coverage of the $\mathrm{TiO}_{2}$ nanoparticles due to the formation of $\mathrm{HS}-\left(\mathrm{CH}_{2}\right)_{10}-\mathrm{COOH}$ spacers connected to the titania nanoparticles. Similarly, Langmuir-Blodgett films of 1,12dodecane dicarboxylic acid were used to connect a monolayer of $\mathrm{TiO}_{2}$ spheres to silicon and glass substrates, upon performing a dehydration-condensation reaction between the carboxyl groups of the dicarboxylic acid and the surface hydroxyl groups on both the substrate and the ceramic spheres [46]. It was claimed that the flexibility of the alkyl chains in the LB film plays a role in improving the capturing of the spheres.

Atomic-layer deposition (ALD) is a gas-phase thin-film deposition method employing self-terminating surface reactions, leading to a linear correlation between the thickness of the layer and the number of deposition cycles. Mixed SAMs with different ratios of $-\mathrm{OH}$ - and $-\mathrm{CH}_{3}$-terminated groups were used to control the surface energy and, as a result, to affect the growth of $\mathrm{TiO}_{2}$ by ALD from titanium isopropoxide and water [47]. Here, two-dimensional growth was observed on SAMcoated substrates with high surface energy, whereas a threedimensional growth mode was found on SAM-coated substrates with low surface energy. The high affinity between $\mathrm{OH}$ groups and the titania precursor was later utilized for the growth of patterned domains of titania on patterned $\mathrm{OH}$-terminated alkanethiolate monolayers on gold [48].

\section{SAMs as a means for studying photocatalysis}

The fact that SAMs are adsorbed irreversibly (or almost irreversibly) on the surface of titanium dioxide makes them a valuable tool for studying fundamental phenomena in photocatalysis, as they provide a way to decouple adsorption and reaction. In this manner, SAMs were utilized to study the so-called "remote degradation" effect, namely the ability to photocatalytically decompose molecules that are located away from the $\mathrm{TiO}_{2}$ surface. Here, a cross-linked SAM of OTS was chemisorbed on well-defined structures comprising alternating microstripes of titania and oxidized silicon of equal width. Upon exposure to UV light, complete mineralization of the OTS located on both types of substrates was observed, even in stripes as wide as 40 $\mu \mathrm{m}$. The measured degradation kinetics on the $\mathrm{TiO}_{2}-\mathrm{Si}$ micropatterned structures was fitted by a bi-exponential fit with two distinct apparent activation energies. Accordingly, it was suggested that oxidizing species leave the titanium dioxide domains to photocatalytically degrade molecules anchored on the remote silicon domains [49]. The remote degradation of OTS on the native oxide of silicon in a structure consisting of alternating stripes of silicon and titania was confirmed later by AFM measurements [16]. Here, XPS measurements showed 
that, upon complete degradation, the siloxane headgroups remain on the $\mathrm{TiO}_{2}$ surface.

Unlike OTS located on silicon in the vicinity of $\mathrm{TiO}_{2}$, monolayers of ODT $\left(\mathrm{CH}_{3}\left(\mathrm{CH}_{2}\right)_{17} \mathrm{SH}\right)$, attached to similar stripes made of gold or platinum located in the vicinity of $\mathrm{TiO}_{2}$, were found to be quite resistant to remote degradation [50,51]. This stability was explained by the high cross section for the reaction between $\mathrm{OH}$ radicals and gold relative to that with silica, and was the basis for the development of photocatalysts having specificity, which utilized the "adsorb \& shuttle" concept.

In a different study, octyltrichlorosilane (OCTS) SAMs chemisorbed on $\mathrm{TiO}_{2}$ microelectrodes in an interdigitated $\mathrm{TiO}_{2} / \mathrm{Pt}$ array were used to study the performance of an electrophotocatalytic cell as a function of applied bias [52]. The applied bias acted to push photogenerated holes to the external surface of the $\mathrm{TiO}_{2}$ layer while pulling the photogenerated electrons to the platinum electrons, thus limiting the recombination rate. Indeed, the degradation rate constant was found to increase as the positive bias on the photocatalyst was raised up to 0.4-0.6 V. Unexpectedly, as the bias was increased above that level, not only did the degradation rate not increase, but in fact the oxidation rate of the SAM began to decrease.

The use of chemisorbed monolayers was crucial for understanding these results. If this phenomenon of counter-productive bias had been measured with a liquid-phase contaminant, one could have claimed that the observed decrease in the rate was due to a significant decrease in the adsorption rate of the target molecule. Here, the fact that the OCTS molecules were chemically and irreversibly attached to the $\mathrm{TiO}_{2}$ electrodes suggested that there had to be another reason. Superoxide radicals, though by themselves ineffective agents for initiating the degradation, may play an important role in the secondary stages of many photocatalytic processes. Hence, a possible explanation could be a shortage of superoxide radicals, as these were formed at the reduction sites, namely at the platinum electrodes. Similar conclusions were drawn also from experiments in air upon studying a nonbiased system consisting of micrometersize domains of $\mathrm{TiO}_{2}$, onto which OTS was chemisorbed in close contact with micrometer-size domains made of gold and platinum [53]. The effect was found to depend on the size of the metallic domain, as well as on the humidity and on the type of metal. Overall, it can be concluded that the use of SAMs to study photocatalysis provided a unique tool to elucidate the role that superoxides may play in photocatalysis, a role that is quite often overlooked.

It is noteworthy that this discussion of the photocatalytic degradation of SAMs is based on the presumption of indirect oxi- dation, i.e., the transformation of the oxidative power of the photoinduced holes into oxygen-containing species, such as $\mathrm{OH}$ radicals. While this indirect oxidation is by all means the prevailing degradation mechanism in almost all organic species physisorbed on the surface of the photocatalyst, the situation can be different when the organic molecules are covalently bound to the surface. Indeed, the photocatalytic degradation of octadecyltrimethoxy silane (ODTMS) SAM on n-type GaN was attributed to a direct mechanism involving electron transfer from the HOMO level of the ODTMS to the valence band of the excited GaN [54]. As a consequence of this direct mechanism in gallium nitride, no remote degradation effects were observed on this photocatalyst. In contrast, the observation of remote degradation on $\mathrm{TiO}_{2}$ indicates that indirect oxidation is the dominant mechanism on titanium dioxide. This conclusion is supported also by the fact that the rate of degradation of alkylphosphonic acid SAMs was found to correlate inversely with the ability of oxygen-containing species to reach the surface by penetrating in between the chains of the monolayer [55].

\section{Surface patterning}

Patterning of surfaces is one of the key issues in many applications involving SAMs. Generally speaking, patterning is manifested by the production of at least two types of surfaces having predesigned geometries that differ in at least one specific property. These properties can be chemical, electronic, optic, acoustic, etc. One of the most popular contrast mechanisms is the contrast between hydrophilic and hydrophobic surfaces, in particular since it can be utilized for selective deposition or growth of a large variety of materials.

The photocatalytic properties of titanium dioxide, enabling it to oxidize SAMs under the relatively weak intensity of UV light, together with the superhydrophilic nature of $\mathrm{TiO}_{2}$ upon exposure to that light and its mechanical and optical characteristics make titanium dioxide a very interesting material for patterning. Indeed, scientific manuscripts on patterning of surfaces are the majority among those articles discussing both titanium dioxide and self-assembled monolayers.

In the context of SAMs, there are a large number of ways in which patterning can be manifested. Partial coverage of the substrate by SAMs, coverage of the surface with more than one type of SAM and selective deposition of materials on prepatterned SAMs, is only a partial list of examples; our discussion of the patterning techniques is organized accordingly, addressing namely the patterning of SAMs on $\mathrm{TiO}_{2}$ and the patterning of $\mathrm{TiO}_{2}$ on SAMs by selective growth. 


\section{Patterning of SAMs on $\mathrm{TiO}_{2}$}

Patterning of SAMs on $\mathrm{TiO}_{2}$ can be obtained by both photocatalytic and nonphotocatalytic routes. Among the nonphotocatalytic methods is microcontact printing (Figure 2) [56], in which SAMs are transferred from stamps of a polymer (for example poly(dimethylsiloxane) (PDMS)) onto oxide substrates upon contact between the stamps and the substrate. Other so-called "soft-lithography" methods (replica molding, microtransfer molding, micromolding in capillaries, and solventassisted micromolding) may work as well [57]. For example, colloidal lithography was used to create gold nanopits on a $\mathrm{TiO}_{2}$ matrix, onto which methyl-terminated alkanethiol SAMs were chemisorbed [58].

While photochemical patterning of SAMs on a variety of substrates without the use of designated photoresists is possible under exposure to $185 \mathrm{~nm}$ light [59], it is limited to specific functional groups, under constrained environments. In contrast, SAMs located on titanium dioxide can be patterned quite easily by photocatalysis (Figure 3A). There is no need for a photoresist, and a standard patterning mask can be used, or otherwise one may imprint water-based ink patterns on the SAMs, which will prevent the photocatalytic degradation of the shadowed area [60]. Instead of exposure through a mask, one may "write" with a well-collimated beam of UV radiation, for example by using an UV laser, or by near-field optical microscope coupled to an UV laser [55].

An interesting (but alas quite cumbersome) way to obtain patterned surfaces with hydrophilic-hydrophobic contrast is to form a prepatterned area comprising $\mathrm{TiO}_{2}$ and another oxide by

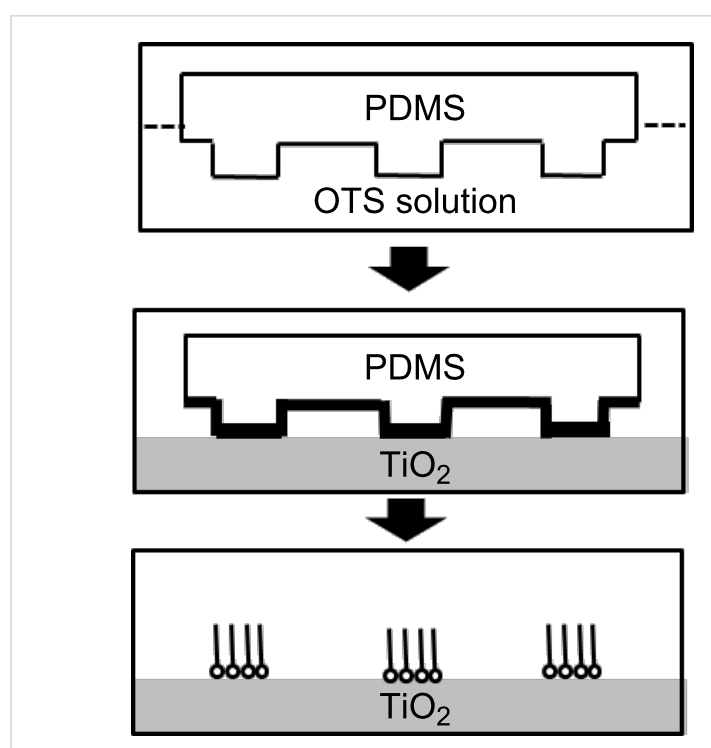

Figure 2: Patterning of SAMs on titanium dioxide by the microcontact printing method.

conventional lithography, and then to attach a hydrophobic SAM to the whole area. The hydrophobic-hydrophilic patterning is then obtained photocatalytically by exposure of the entire area to UV light, thus, degrading the SAM from the $\mathrm{TiO}_{2}$ domains. This approach was demonstrated with $\mathrm{CuO}$ domains prepared by oxidation of $\mathrm{Cu}$ that had been deposited by electroless deposition on silver [61]. The silver was deposited on a titania film by photocatalytic reduction. Thus, in this case the photocatalytic properties of titanium dioxide were exploited twice, i.e., for the deposition of the silver domains and for the degradation of the SAMs chemisorbed on the photocatalyst
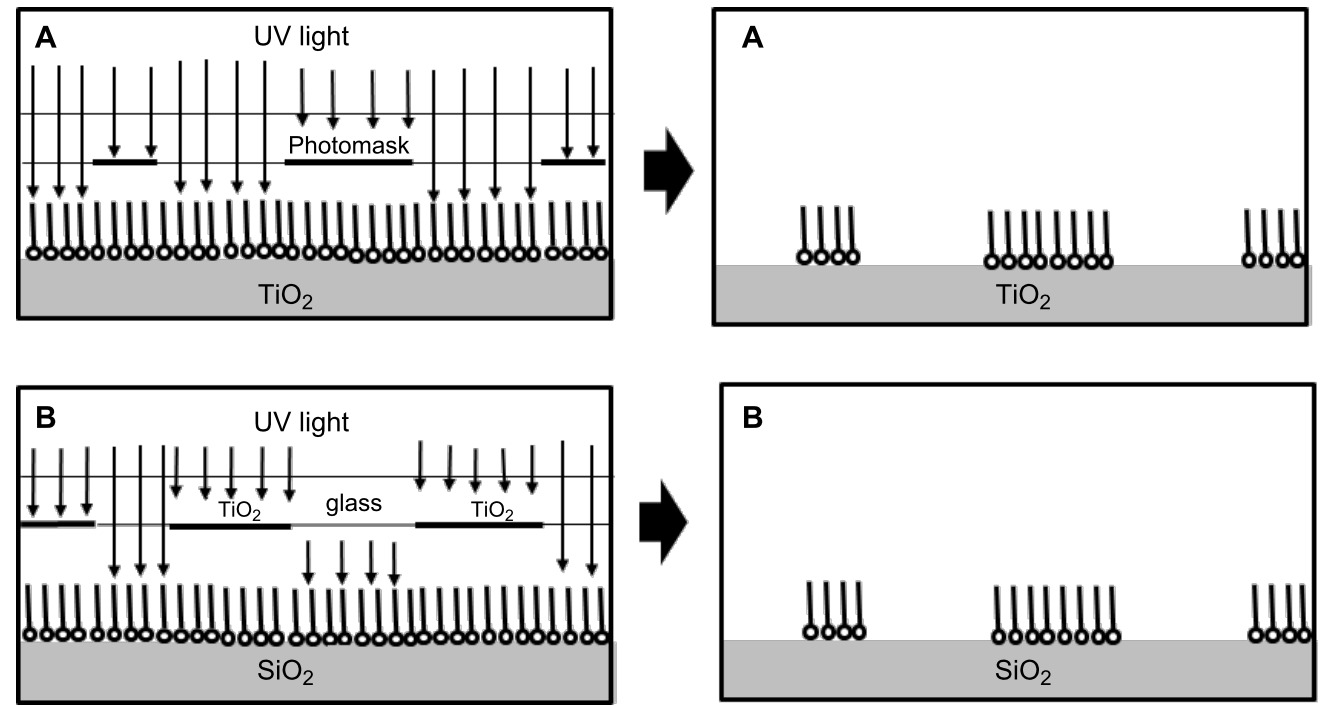

Figure 3: Photocatalytic patterning of SAMs. (A) SAMs on $\mathrm{TiO}_{2}(\mathrm{~B})$ SAMs on inert substrates. 
domain. It is noteworthy that the hydrophobic spots were relatively large $(0.5 \mathrm{~mm}$ in diameter), such that remote degradation effects were less acute for this system.

One of the problems associated with the formation of hydrophobic-hydrophilic contrast patterns comprising a hydrophobic SAM on $\mathrm{TiO}_{2}$ and superhydrophilic titanium dioxide is the loss in contrast over time, which is due to eventual contamination of the $\mathrm{TiO}_{2}$ surface upon adsorption of organic molecules from the air. Exposure to UV light may degrade these molecules, thus, restoring superhydrophilicity; however, it might also degrade the organic SAM and therefore cannot be used to solve the problem of contrast loss. A novel approach for the construction of a renewable superhydrophobic-superhydrophilic surface was presented by Nishimoto et al. [62]. The approach is based on through-mask photocatalytic patterning of hydrophobic SAM on $\mathrm{TiO}_{2}$, followed by deposition of boehmite $\left(\mathrm{AlOOH} \cdot n \mathrm{H}_{2} \mathrm{O}\right)$ on the exposed $\mathrm{TiO}_{2}$ domains. Then, a heat-treatment step converted the boehmite into $\mathrm{Al}_{2} \mathrm{O}_{3}$, while oxidizing the SAMs, forming a patterned $\mathrm{TiO}_{2}$-boehmite surface. A hydrophobic SAM was then attached to both types of domains, which then went through a second step of exposure to UV light. At the end of the process a negative image of the first-step surface was obtained, consisting of superhydrophilic $\mathrm{TiO}_{2}$ domains and superhydrophobic domains anchored to alumina. In that way, the restoration of hydrophilic contrast by exposure to UV was expected not to take its toll on the hydrophobic SAMs. With respect to remote degradation, the fact that the inert substrate here is alumina and not silica may assist to preserve the SAMs, as can be inferred from a comparison of the remote degradation effects of SAMs on silica to those of SAMs on alumina [51].

Remote degradation effects are not necessarily destructive when it comes to the patterning of SAMs. In fact, they can be utilized to pattern SAMs on inert surfaces (Figure 3B). The technique was demonstrated by Lee and Sung, who used a quartz mask containing patterned $\mathrm{TiO}_{2}$ in order to pattern an octadecylsiloxane SAM on silicon [63]. Once patterned, ultra-thin layers of $\mathrm{ZrO}_{2}$ were deposited by atomic-layer deposition on the exposed parts of the silicon substrate. The reported spatial resolution was striking: The nominal width of $\mathrm{ZrO}_{2}$ lines and SAMcoated Si lines was approximately $0.5 \mu \mathrm{m}$. This relatively high resolution should be attributed to the intimate contact between the $\mathrm{TiO}_{2}$ mask and the SAM-coated silicon as well as to the short exposure time, which minimized the blurring.

Another example of photocatalytic patterning of SAMs on inert substrates is the patterning of perfluorodecanethiol SAM on gold by a through-mask back exposure of thin films of titania located at a distance of $12.5 \mu \mathrm{m}$ from the SAM-coated gold
[64]. The quality of the patterned surface was examined by immobilizing a fluorescent dye on the oxidized regions of the patterned gold surface. The same method was used to pattern enzymes on a gold surface, by the attachment of fluorescein isothiocyanate labeled peroxidase (FITC-POD) onto the hydrophilic regions. Unfortunately, no details were given regarding the thickness of the $\mathrm{TiO}_{2}$ layer and the wavelength. Such details could be of high importance for analyzing the significance of the data in this back-exposure configuration.

Photocatalytic lithography by remote degradation was also demonstrated by the formation of grayscale gradients in thiolated SAMs anchored to gold located as far as $60 \mu \mathrm{m}$ from a $\mathrm{TiO}_{2}$ thin film on quartz, back-irradiated through a mask [65]. The gaps in the thiolated SAM were then filled with 11-mercapto-1-undecanol or with $1 H, 1 H, 2 H, 2 H$-perfluorodecanethiol. The flux during irradiation was quite high $\left(17 \mathrm{~mW} / \mathrm{cm}^{2}\right)$. The apparent contradiction between this study and works that reported the high stability of SAMs on gold towards remote degradation [50] may be explained by the different position of the SAMs relative to the source of the oxidizing species and the high UV flux in the back-irradiation experiments.

An interesting, inexpensive way to use photocatalysis for the formation of patterns having hydrophobic-hydrophilic contrast was presented by Bai et al. [66]. Here, $\mathrm{TiO}_{2}$ particles in solution were used to pattern an OTS monolayer on mica sheets, the size of the islands and concentration being affected by the UV flux impinging on the surface, as evidenced by AFM and wettability measurements.

The phenomenon of remote degradation raises a question regarding the fidelity of patterns obtained by through-mask exposure techniques. Indeed, exposure of OTS-coated $\mathrm{TiO}_{2}$ to $254 \mathrm{~nm}$ light through a quartz mask covered with chromium stripes (40 $\mu \mathrm{m}$ in width and distance) caused a complete degradation of the alkyl chains, including those in the "dark" regions [67]. This does not necessarily contradict the reports on patterning presented above, since analysis of the kinetics revealed that the degradation rate in the exposed areas was 2-20 times faster than in the dark areas, and hence, obtaining a reasonable contrast is still possible. However, it definitively demonstrated that patterning can be very sensitive to overexposure, and that in terms of contrast, the best resolution that can be achieved with photocatalytic patterning is expected to be no better than a few microns. Moreover, if one accepts the notion that the dominant mechanism of remote degradation is photoinduced homolysis of photocatalytically formed hydrogen peroxide, then an important outcome is that structures that are patterned by exposure to $365 \mathrm{~nm}$ light may be sharper than 
structures patterned by $254 \mathrm{~nm}$ light. This conclusion, which seems contradictory to conventional wisdom, stems from the fact that the quantum efficiency of the generation of $\mathrm{OH}$-radicals by photohomolysis of $\mathrm{H}_{2} \mathrm{O}_{2}$ with $365 \mathrm{~nm}$ photons is 110 times smaller than that with $254 \mathrm{~nm}$ photons [68].

\section{Patterning of $\mathrm{TiO}_{2}$ by selective growth on SAMs}

Probably the most popular way by which SAMs have been used as a means to obtain patterned $\mathrm{TiO}_{2}$ films is through site-selective deposition (SSD) of the oxide on prepatterned SAMs [69]. The concept here is to pattern SAMs on substrates, either by complete removal or by site-specific tailoring of the outer groups, thus forming areas with high tendency for titania growth, coexisting with domains onto which titania will not grow. It should be pointed out that the SSD technique is not limited to the deposition of titanium dioxide and was utilized for patterned growth of other oxides such as $\mathrm{In}_{2} \mathrm{O}_{3}$ [70], $\mathrm{Ta}_{2} \mathrm{O}_{5}$, $\mathrm{SnO}_{2}$ and $\mathrm{SrTiO}_{3}$ [69].

The most popular means for selective growth is direct siteselective deposition (Figure 4), based on patterning of SAMs on a substrate (either by exposure to $185 \mathrm{~nm}$ light or by conventional photolithography), followed by nucleation and growth of $\mathrm{TiO}_{2}$ on areas that have been depleted of the SAMs. As an example, one may mention the patterning of OTS into methylterminated regions and silanol-terminated regions, onto which amorphous titanium dioxide formed from titanium dichloride diethoxide (TDD) was deposited either from the liquid phase (D-40) [71] or from the gas phase [72]. The latter was reported to yield higher quality films due to a lack of bulk nucleation. In a later study a comparison was made between three types of precursors, namely TDD, titanium tetrachloride (TC) and titanium tetraethoxide (TE), acting on deep UV-exposed OTS and PTCS (phenyltrichlorosilane) [73]. Quite surprisingly, it was found that the contrast in the patterns of the grown oxide depended on the type of precursor. While TC or TDD formed $\mathrm{TiO}_{2}$ on the hydrophilic silanol groups but not on the hydrophobic methyl groups of OTS, TE induced $\mathrm{TiO}_{2}$ growth on both types of substrates without any preference. Regardless of the precursor, the obtained $\mathrm{TiO}_{2}$ films were amorphous. Conversion to anatase took place at $300{ }^{\circ} \mathrm{C}$ when TC was the precursor, whereas a temperature of $400{ }^{\circ} \mathrm{C}$ was required when TDD or TE were used as precursors. To improve the contrast in SSD growth on a patterned silanol-hydrophobic SAM surface one may use sonication, which has been demonstrated to remove loosely adhered $\mathrm{TiO}_{2}$ particles from domains on which deposition was undesirable $[74,75]$.

Exposure to deep UV through a photomask was also used for partial oxidation of SAMs of octadecyltrichlorosilane, phenyltrichlorosilane, vinyltrichlorosilane and $p$-tolyltrichlorosilane on an (aminopropyl)triethoxysilane grafted poly(ethylene terephthalate) surface. Subsequently, $\mathrm{TiO}_{2}$ was grown selectively by LPD on the oxidized domains (Figure 5). It was found that SAMs containing aromatic rings were the most suitable for growing titania, producing strongly adhering films with distinct $\mathrm{TiO}_{2}$ micropatterns [41]. To improve selectivity, a shielding reagent, reversibly adsorbed on the nonexposed domains of a $p$-tolyltrichlorosilane SAM, was added prior to the $\mathrm{TiO}_{2}$ growth step [76]. This shielding reagent, dodecylbenzene sodium sulfonate, was chosen based on its tendency, in aqueous solutions, to attach only to hydrophobically-terminated SAMs, due to its amphiphilic nature. It is noteworthy that bubbling air to

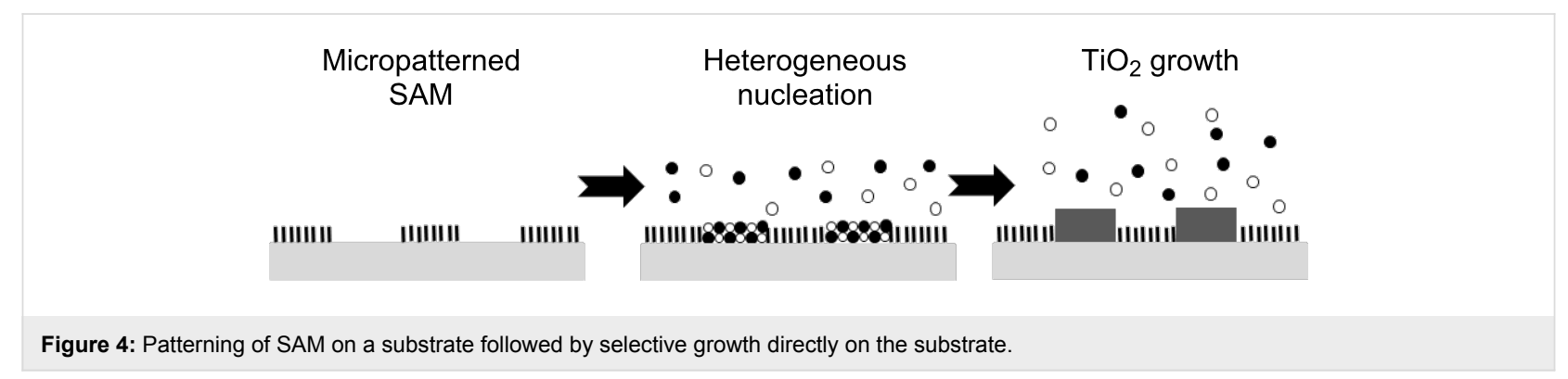

SAM

Patterned SAM $\mathrm{TiO}_{2}$ growth

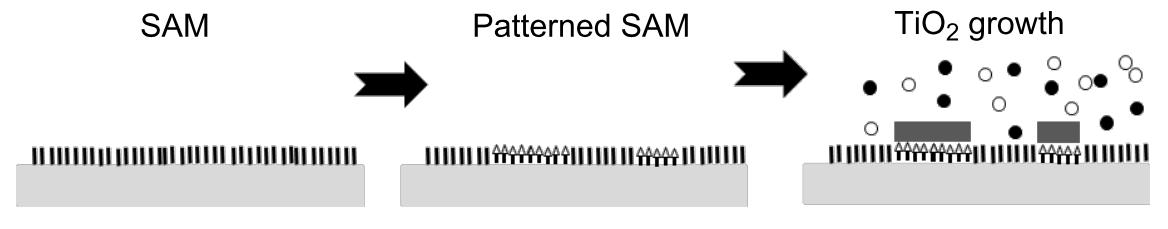

Figure 5: Partial oxidation of SAMs at predesigned locations followed by $\mathrm{TiO}_{2}$ growth on the partially oxidized domains. 
constantly replace the LPD solution close to the surface can be quite beneficial for forming crack-free $\mathrm{TiO}_{2}$ films, as was demonstrated with patterned SAMs of heptadecafluoro-1,1,2,2tetrahydrodecyltrichlorosilane (HFDTS) [77]. Another example of the approach portrayed in Figure 2B was the patterned oxidation of thioacetate- $\left(-\mathrm{SCOCH}_{3}\right)$ terminated SAMs to form patterned sulfonate-terminated domains onto which $\mathrm{TiO}_{2}$ was grown [78].

A non-photoinduced means to pattern SAMs for selective deposition is microcontact printing (Figure 2). For example, microcontact printing of sulfonic acid terminated SAMs facilitated the growth of patterned $\mathrm{TiO}_{2}$ from a solution containing titanium sulfate and hydrogen peroxide [34]. Another example is the transfer of OTS SAM onto silica followed by selective ALD growth of titanium dioxide on the noncoated areas [79]. Likewise, a technique called "edge-transfer lithography" was applied to form lines of titanium dioxide nanoparticles with nanometer-scale resolution [80]. Here, transfer of SAMs from the edges of micron-scale-patterned elastomeric stamps onto silica produced nanometer-scale patterned SAMs, with line widths as small as $60 \mathrm{~nm}$. Such thin lines were obtained by a dewetting and blow-drying process, which trapped silane solution only in the recesses of the molded stamp. In a different work, OTS was deposited by microcontact printing onto both external sides of a nanoporous polycarbonate filter. As a consequence, the ALD growth of titanium dioxide was limited to the inner walls of the polycarbonate filter. In that way, the performance of 100-800 ALD cycles followed by the etching away of the polycarbonate template with chloroform yielded $\mathrm{TiO}_{2}$ nanotubes, whose diameter could be predetermined according to the diameter of the pores in the PC filter [81].
Patterning of SAMs en route for selective deposition can be achieved by introducing a physical barrier for the deposition of SAMs, followed by $\mathrm{TiO}_{2}$ growth once the barrier is removed. In that manner, coined "contact area lithography" (CAL), round nanoparticles were used to cover a silica surface, thus forming a close-packed structure with a hexagonal pattern of nanometersized contact dots (Figure 6). Then, OTS SAMs were deposited everywhere except for on the contact dots, facilitating the ALD growth of nanodisks of $\mathrm{TiO}_{2}$ from a titanium tetraisopropoxide precursor [82].

It is noteworthy that the growth rate of anatase on top of SAMs (methyl-terminated or even amino-terminated) is significantly lower than that measured on top of amorphous $\mathrm{TiO}_{2}$ underlayer. This was exploited for the growth of a patterned anatase layer on top of amorphous $\mathrm{TiO}_{2}$ grown on patterned $\mathrm{OH}$-terminated SAMs [83].

Although SAMs were used to obtain patterned $\mathrm{TiO}_{2}$, mainly by directing the deposition of titania, it is possible to pattern $\mathrm{TiO}_{2}$ by directing its etching instead of its growth (Figure 7). An interesting example is the patterning of an area made of $\mathrm{TiO}_{2}$ nanotubes, formed by anodization of titanium in HF. Here, SAMs of $1 H, 1 H, 2 H, 2 H$-perfluorooctyl-triethoxysilane were chemisorbed on selected areas in the nanotube array and served to selectively protect the nanotubes upon immersion in HF [84].

\section{Electron transfer in SAMs connected to $\mathrm{TiO}_{2}$}

Electron transfer through SAMs has been studied quite thoroughly for both organothiolated SAMs on metals and organosilanes on silicon. The appearance of dye-sensitized solar cells [85], based on (disordered) dye molecules attached to the

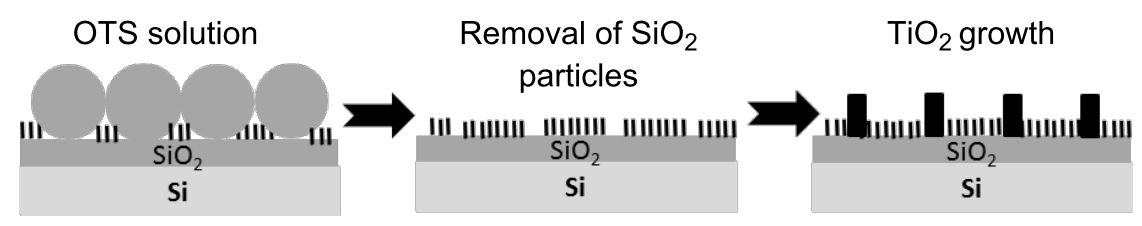

Figure 6: Patterned growth of $\mathrm{TiO}_{2}$ by "contact area lithography" (CAL) (after [82]).

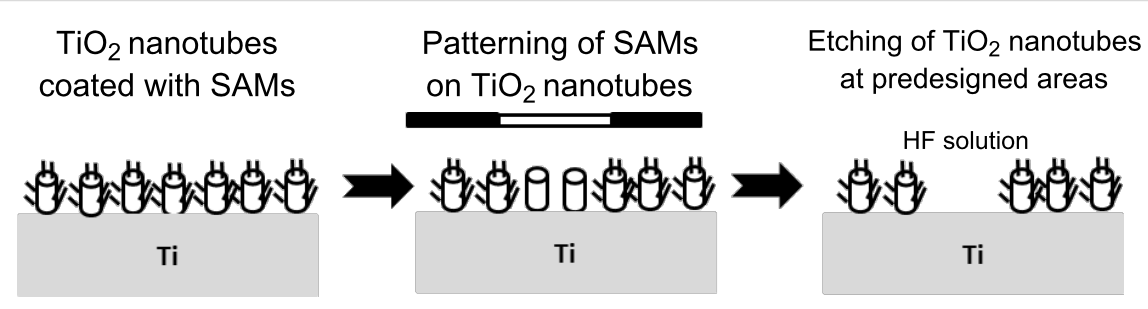

Figure 7: Patterning of a surface containing $\mathrm{TiO}_{2}$ nanotubes by localized etching, by using patterned SAMs to protect selected areas (after [84]). 
surface of nanoparticulate titanium dioxide, provoked interest also in the charge transport from SAMs to titanium dioxide. In many cases, as detailed below, the SAMs serve as mediators between the sensitizing molecules and the surface, and hence are required to exhibit good conductivity along the molecule, minimal contact resistance, and, no less important, a set of energy levels that can support vectorial charge transfer. Although many of the studies in this area are phenomenological they provide the necessary background required for the development of a variety of microelectronic devices such as solar cells, transistors and capacitors. It is noteworthy that in many publications discussing charge transport between SAMs and titanium dioxide, the characterization of the prepared films is somewhat partial; it is thus very rare to find manuscripts that provide data on the organization and orientation of the adsorbed molecules as well as on their surface concentration.

The finding that $\mathrm{C}_{60}$ may transfer electrons to titanium dioxide upon illumination with visible light [86] led to the study of a system in which the $\mathrm{C}_{60}$ is anchored to the titanium dioxide through a SAM mediator. The mediator comprised salicylic acid (attached to the $\mathrm{TiO}_{2}$ surface through its carboxylate group) connected to a pyrrodine group of a modified $\mathrm{C}_{60}$ [87]. An agreement between the measured photocurrent action spectrum and the absorption spectrum of the modified fullerene served as an indication that the photoactive species was the modified fullerene. A photon-to-current conversion efficiency as high as $15 \%$ was measured, demonstrating the usefulness of using SAM mediators.

The same concept of using SAMs as mediators was demonstrated in a system comprising quantum dots and selfassembled-monolayer-coated titanium dioxide. Here, cadmium-sulfur-selenium (CdSSe) quantum dots were physically attached to hydrothermally synthesized anatase $\mathrm{TiO}_{2}$ nanobelts, onto which SAMs of long chain carboxylic acids, exposing hydrophobic terminating groups, were chemisorbed [88]. An UV-induced compressive force between the nanoparticles and the $\mathrm{TiO}_{2}$ nanobelts could be inferred based on Raman spectroscopy. To our understanding, this compressive force may compensate to some extent for the lack of chemical bonding between the quantum dots and the terminating groups of the monolayer, thus, enabling the high photocurrent response measured for this system.

Another study on charge transport between SAMs and $\mathrm{TiO}_{2}$ was based on a mixed-monolayer configuration. Here, a selfassembled monolayer of a carotenoid (trans-8'-apo- $\beta$-caroten8'-oic acid) was adsorbed on $\mathrm{TiO}_{2}$. Long-chain molecules of pheophytin were immobilized in between the long-chain carotenoids by virtue of $\mathrm{VdW}$ forces. It was shown that excita- tion of the pheophytin molecules by $670 \mathrm{~nm}$ light was quenched reductively by electron transfer from the carotenoid [89]. It was suggested that the charged pheophytin recovers back to the parent molecule predominantly by injecting an electron into the $\mathrm{TiO}_{2}$ conduction band, thus, facilitating the observation of a long-lived carotenoid radical cation. A claim was made that similar paths yielding long-lived charge separation situations may be relevant also in natural photosynthetic systems, and should be considered in the development of dye-sensitized solar cells.

In certain cases, feasibility studies with $\mathrm{TiO}_{2}$-containing systems were later implemented in devices that are constructed on other substrates. As an example, a self-assembled monolayer of 5-cyano-2-(butyl-4-phosphonic acid)-3-butylthiophene (CNBTPA) was formed on $\mathrm{TiO}_{2}$ by using its phosphonic acid group as a binding group. Once chemisorbed, the monolayer served to attach molecules of $\alpha, \omega$-dicyano substituted $\beta, \beta^{\prime}-$ dibutylquaterthiophene (DCNDBQT) molecules by forming a hydrogen bond between the cyano group of CNBTPA and a hydrogen on the thiophene ring of DCNDBQT, and by forming a hydrogen bond between the cyano group of DCNDBQT and a hydrogen on the thiophene ring of CNBTPA [90]. A quasiperpendicular structure of the CNBTPA-DCNDBQT layer relative to the $\mathrm{TiO}_{2}$ surface was inferred, suggesting optimal orbital overlap between neighboring thiophene rings. The same substituted oligothiophene was then used to form a nanoscopic organic field-effect transistor (OFET), albeit not on $\mathrm{TiO}_{2}$ but on $\mathrm{Si} / \mathrm{SiO}_{2}$ substrate.

\section{Applications}

The study of the ways by which SAMs are attached to titanium dioxide (and, in a complementary manner, ways by which $\mathrm{TiO}_{2}$ is grown on SAMs) as well as the study of fundamental phenomena and the developing of patterning techniques, have paved the way for the utilization of systems comprising SAMs and $\mathrm{TiO}_{2}$ for a variety of applications. The following section discusses the main applications presented so far.

\section{$\mathrm{TiO}_{2}$-SAMs in electronic devices}

The large dielectric constant $k$ of $\mathrm{TiO}_{2}(25<k<30)$ compared with that of silica $(k=3.9)$, as well as its refractory properties, suggest its use in MOSFET technology [91]. In that respect, it is interesting to mention that the dielectric constant of amorphous $\mathrm{TiO}_{2}$ grown on patterned OTS from titanic acid $\left(\mathrm{H}_{2} \mathrm{TiO}_{3}\right)$ [92] was estimated to be 63 at $100 \mathrm{kHz}$, significantly larger than the reported values of 22 measured for biomimetically deposited amorphous $\mathrm{TiO}_{2}$ [93]. This was attributed to the existence of small crystallized particles. A significant drawback in the use of $\mathrm{TiO}_{2}$ for microelectronic purposes is the relatively high leakage current (as high as $4.3 \times 10^{-8} \mathrm{~A} \mathrm{~cm}^{-2}$ at $1 \mathrm{~V}$ and a thickness of 
$306 \mathrm{~nm}$ ) and the linear decrease in the dielectric constant as a function of frequency (from $k=160$ at $1 \mathrm{kHz}$ to $k=23$ at $1 \mathrm{mHz}$ ) [92]. These were explained by the presence of interface states and impurities such as $\mathrm{OH}^{-}$and $\mathrm{H}_{2} \mathrm{O}$ in the film. Still, well-behaved MOSFET transistors with a $\mathrm{TiO}_{2}$ gate oxide were demonstrated already in 1997 [94], prior to the full development of patterning technologies. Likewise, a miniature capacitor, made of an oxide-SAM- $\mathrm{TiO}_{2}$ sandwiched structure, was presented already in 1998 [95].

The possibility to deposit $\mathrm{TiO}_{2}$ on top of sulfonate-terminated SAMs was utilized to form metal-oxide-metal (MOM) heterojunction nanowires by a "bottom-up" approach [96]. Here, $\mathrm{Au}-\mathrm{TiO}_{2}-\mathrm{Au}$ nanowires were prepared within nanoholes of anodic aluminum oxide templates. The preparation procedure included the deposition of gold by electroplating, chemisorption of 1,8-octanedithiol (HS- $\left.\left(\mathrm{CH}_{2}\right)_{8}-\mathrm{SH}\right)$, oxidation of the terminal thiol groups to form $\omega$-sulfonate groups, deposition of polycrystalline anatase using $\mathrm{Ti}(\mathrm{OPr})_{4}$ dissolved in a water-ethanol mixture, and capping of the $\mathrm{TiO}_{2}$ with electroplated gold.

Self-assembled monolayers, with their ability to attach both to inorganic and organic materials may have a large potential in hybrid microelectronic systems containing titanium dioxide together with organic components. Along this line, the improvement of the performance of organic field-effect transistors (OFETs) by introducing SAMs was observed with OFETs comprising a titanium gate, dielectric layer of $\mathrm{TiO}_{2}$ prepared by anodization, and a poly(triarylamine (PTAA)) layer (alternatively a pentacene layer) that served to form the source and the drain of the transistor [97]. Here, the addition of an OTS layer between the $\mathrm{TiO}_{2}$ and the source-drain layer was found to increase the field-effect mobility (calculated in the saturation regime) by two orders of magnitude (with PTAA) or by a factor of 2 (with pentacene).

SAMs may assist in the preparation of hybrid electronic components not only by forming the connection between organic and inorganic layers but also by facilitating self-patterning. In that manner photopatternable SAMs of $1 H, 1 H, 2 H, 2 H$-perfluorododecyltrichlorosilane were used as a template for self-localization of conducting polymers en route to the formation of polymer-based transistors [98]. Here, the source and drain electrodes were formed by spin coating an aqueous solution of poly(3,4-ethylenedioxythiophene) (PEDOT) on $\mathrm{TiO}_{2} / \mathrm{SAM}$, resulting in dewetting and self-localization of the solution within the exposed domains. The substrates were then further coated with poly(3-hexylthiophene) (P3HT). Conformity of the structure was found to depend heavily on the humidity conditions during exposure, since too high a humidity resulted in remote degradation of nonirradiated areas, which could lead to an excess coverage of PEDOT. For the same reason (prevention of remote degradation) $365 \mathrm{~nm}$ light was found to give sharper patterns than $254 \mathrm{~nm}$ light.

The use of SAMs on oxidized silicon in order to reduce friction is well documented. In a similar manner, SAMs on titanium dioxide were utilized to simultaneously solve the problems of wear and stiction in microelectromechanical (MEMS) devices. Here, a thin $(10 \mathrm{~nm})$ layer of $\mathrm{TiO}_{2}$ was coated by the ALD technique onto polysilicon substrates. A SAM of $\mathrm{CF}_{3}\left(\mathrm{CF}_{2}\right)_{7}\left(\mathrm{CH}_{2}\right)_{2} \mathrm{SiCl}_{3}$ (FDTS) was then chemisorbed on the titania layer [99]. Tribological measurements showed that the static-friction coefficient was dominated by the presence of FDTS as an external layer, as manifested by the fact that the coefficients of FDTS on $\mathrm{TiO}_{2}$ and on $\mathrm{SiO}_{2}$ were nine times lower than those of $\mathrm{SiO}_{2}$ and three times lower than those of $\mathrm{TiO}_{2}$. At the same time, wear tests showed that the lifetimes of moving parts were similar to those obtained with polysiliconcoated titanium dioxide, namely 1.5-3.0 times longer than those of noncoated polysilicon.

\section{Solar cells}

One of the most popular (if not the most popular) areas utilizing structures containing SAMs and titanium dioxide, is photovoltaics. In almost all designs these structures are characterized by the SAM serving as a mediator between the photosensitizer and the titanium dioxide acceptor. A variety of photosensitizers have been used: From the conventional ruthenium-based dyes to conductive polymers, $\mathrm{C}_{60}$ and inorganic quantum dots. Likewise, a variety of SAMs have been used, with various anchoring groups, including phosphonic acids, silanes, and carboxylic acids. Unfortunately, while the motivation for using SAMs as mediators ensuring vectorial charge transfer is clear, the results obtained so far are still insufficient in terms of cost and efficiency to justify commercial scale production. This does not necessarily mean that the approach of using SAMs as mediators is doomed to fail. On the contrary, analysis shows that this direction draws increasing attention.

Polyaniline (PANI), which has a bandgap of $2.8 \mathrm{eV}$, compared with $3.2 \mathrm{eV}$ of $\mathrm{TiO}_{2}$, was used as a sensitizer, absorbing visible light and transferring photoinduced charge to the titanium dioxide, by virtue of good matching between its LUMO level and the conduction band of $\mathrm{TiO}_{2}$. PANI adheres to titanium dioxide by physical adsorption, and thus it was thought that a mediator that forms a strong interaction with both would improve charge transport. Indeed, silane-bearing aniline compound $\left(\mathrm{C}_{6} \mathrm{H}_{5} \mathrm{NHC}_{3} \mathrm{H}_{6} \mathrm{Si}(\mathrm{OMe})_{3}\right)$ was used to form solvent-free quasi-solid solar cells based on acid-doped polyaniline, but the efficiency was quite modest $(0.12 \%)$ [100]. Another mediator 
between PANI and $\mathrm{TiO}_{2}$ was aminopropylsilane, resulting in improved thermal stability of PANI and enhanced photocatalytic degradation rate of methyl orange molecules under sunlight, which was attributed to the sensitizing effect of PANI [14].

In a quest to replace expensive dyes in DSSCs, Senadeera et al. used grafted polypyrrole films covalently bonded to selfassembled monolayers of 3-(trimethoxysilyl)propyl methacrylate attached to mesoporous $\mathrm{TiO}_{2}$ substrates [101]. Although the overall performance was poor, a comparative study showed that polypyrrole could be used more efficiently as a sensitizer for $\mathrm{TiO}_{2}$ when covalently attached through the SAM than it could without the SAM.

The interface between $\mathrm{TiO}_{2}$ and poly(3-hexylthiophene) $/[6,6$,$] phenylC 60$ butyric acid methyl ester (P3HT/ PCBM), in a based-inverted bulk-heterojunction (BHJ) solar cell, was modified by a series of carboxylic acid functionalized SAMs [102]. The presence of SAMs acted to reduce the contact resistance by passivating the surface trap sites at the $\mathrm{TiO}_{2}$ surface, enhancing the electronic coupling between the $\mathrm{TiO}_{2}$ and the organic layer, and also improved the growth mode and morphology of the upper organic layer. The largest enhancement was observed with a SAM of $\mathrm{C}_{60}$-substituted benzoic acid. Here, the efficiency with the buried SAM layer was 3.8\%, compared with $2.8 \%$ in the absence of a SAM interlayer.

In two similar systems, two SAMs attached to $\mathrm{TiO}_{2}$ through phosphonic acid (2-oligothiophene phosphonic acid and $\omega$-(2thienyl)alkyl phosphonic acid) were used as interface modifiers on $\mathrm{TiO}_{2}$ to increase compatibility with poly(3-hexylthiophene) (P3HT) [103]. The photoluminescence (PL)-quenching efficiency and the short-circuit current density of photovoltaic cells having this configuration were found to increase with the number of thiophene rings and as the alkyl-chain length decreased. Here, a drop in the LUMO level of the interface modifiers increased the photocurrent at the expense of the opencircuit voltage. It should be noted that the observation of correlation between structural parameters in the polymer and its photovoltaic performance is important as it may provide a strategy for stabilizing inorganic particles in the fabrication of high efficiency organic-inorganic photovoltaic devices.

The recent interest in utilizing quantum dots (QDs) for photovoltaics also has its influence on SAMs and titanium dioxide, as more and more cases in which SAMs are used as mediators between QDs and titanium dioxide are published. For example, a self-assembled monolayer of 3-mercaptopropyl-trimethoxysilane was preassembled onto a mesoporous $\mathrm{TiO}_{2}$ film to be used as a surface-modified layer to induce the growth of $\mathrm{CdSe}$ quantum dots [104]. Here, it was claimed that the terminal thiol groups increased the nucleation and growth rate of CdSe QDs formed by the successive ionic layer adsorption and reaction (SILAR) process. The large uniformity of the CdSe films formed in that way inhibited charge recombination at the electrode-electrolyte interface, and as a consequence, higher efficiency in CdSe-sensitized DSSC solar cells was obtained. In a similar manner, SAMs of mercaptoacetic acid served as substrates for the growth of quantum dots of cadmium sulfide by the same SILAR method [105]. CdS QDs were also produced on SAMs attached to $\mathrm{TiO}_{2}$ by a phosphonic acid headgroup [106]. The SILAR procedure here comprised successive cycles consisting of exposure to $\mathrm{CdSO}_{4}$, rinsing in DI water, immersion in $\mathrm{Na}_{2} \mathrm{~S}$ and a second rinsing in DI water. The solar-cell performance was found to depend on the number of SILAR cycles (it was claimed that above six cycles, the CdS may aggregate or form recombination centers). The efficiency obtained with 3-aminopropyl phosphonic acid (APPA), 3-phosphonopropionic acid (PPA), and 1-butylphosphonic acid (BPA) $(0.44 \%)$ was as much as three times higher than that measured in the absence of SAMs. Quite surprisingly, no tailgroup dependence was found, suggesting in this case that the CdS nanoparticles were not sitting at the surface of the SAMs, but were rather penetrating into the SAM network such that they resided close to the $\mathrm{SAM} / \mathrm{TiO}_{2}$ interface.

This part would not be complete without reference to another particular effect of SAMs in a totally different design. This is namely the use of SAMs anchored to titanium dioxide as a means to improve the stability and durability of dye molecules also anchored to $\mathrm{TiO}_{2}$. This effect was well demonstrated in the coadsorbption of 1-decylphosphonic acid together with a heteroleptic ruthenium sensitizer that contained two long amphiphilic chains attached to its bipyridine rings (Z-907) [107]. Here, the presence of the SAMs was found to significantly reduce the drop in the open-circuit voltage (from $90 \mathrm{mV}$ to $20 \mathrm{mV}$ ) measured following $1000 \mathrm{~h}$ of aging at $80{ }^{\circ} \mathrm{C}$. This was achieved without any deleterious effect on the initial performance (approx. 7\% efficiency). This enhanced stability was attributed to the ability of the SAM to exclude water molecules from the interface, probably by the formation of a hydrophobic barrier made from the long chained phosphonates interacting with the long amphiphilic chains of the dye.

\section{Offset printing}

Current offset printing technology is based on anodized aluminum plates patterned, by photosensitive means, into hydrophobic and hydrophilic regions to be wet selectively by oil-based ink and water, respectively. Color printing requires usually 3-4 plates that cannot be recovered. A new type of offset-printing plate that can be reused many times and with a 
resolution of up to 150 lines per inch was presented recently. This new offset technology is based on photocatalytic patterning of SAM-coated $\mathrm{TiO}_{2}$ into superhydrophobic and superhydrophilic regions [108]. Here, the patterning of the SAMs chemisorbed on the $\mathrm{TiO}_{2}$-coated plates was performed by using an ink-jet printer to deposit patterned ink, which served as a photomask shielding the SAMs during UV exposure [109].

Loading films or particles of nanoporous titanium dioxide with nanoparticles of silver (for example by photocatalytic deposition upon exposure to UV light) was shown to produce brownish-grey colored surfaces. Illumination of these surfaces by monochromatic visible light changes the color of the $\mathrm{Ag}-\mathrm{TiO}_{2}$ system to that of the incident light, due to reoxidation, causing the silver nanoparticles that had already absorbed at this specific wavelength to lose their ability to absorb more photons at this same wavelength. This phenomenon, termed "multicolor photochromism" [110] can, in principle, be utilized to form rewritable color papers and paints, or even optical memories. One of the problems preventing this application is the gradual bleaching of the color due to nonpreferential absorption upon exposure to white light. In this context, it was found that modification of the $\mathrm{Ag}-\mathrm{TiO}_{2}$ films with alkanethiol or fluoroalkanethiol SAMs may help to suppress bleaching, either by preventing the oxidative dissolution of silver or by blocking the electron transfer from silver to oxygen [111]. The mechanism for bleaching suppression is the same as that for coloring suppression, hence reactivation is needed. This reactivation could be obtained by photocatalytic decomposition of the ODT monolayers on the silver by exposure to UV light, and by relying on the remote degradation effect of $\mathrm{TiO}_{2}$ as discussed above.

\section{SAMs for selective photocatalysis}

Heterogeneous photocatalysis, being based on oxidation by hydroxyl radicals, is known to hardly distinguish between different target molecules. Since some contaminants are more toxic than others, and since some contaminants are readily degradable by biological means while others are nonbiodegradable, there is an obvious need to develop selective photocatalysts that will address streams containing multiple contaminants in a manner that would handle preferentially those contaminants that are either highly toxic and/or nonbiodegradable [112].

A few years ago it was proposed that a structure comprising SAMs located in the vicinity of titanium dioxide domains could be used en route to achieve preferential degradation of toxic contaminants. The principle was to use SAMs on inert substrates as molecular recognition platforms able to selec- tively physisorb specific target molecules. Once physisorbed, the target molecules diffuse from the inert, adsorption sites to the photocatalytic domains, where they are photocatalytically degraded (Figure 8). The feasibility of this approach was first demonstrated by constructing metallic microdomains, onto which self-assembled monolayers of thiolated $\beta$-cyclodextrin were chemisorbed. The cavity of the $\beta$-cyclodextrin served as a molecular-recognition site for 2-methyl-1,4-naphthoquinone (2MNQ). The measured degradation rate ratio between $2 \mathrm{MNQ}$ and benzene was 8.1 , compared with 0.8 in the absence of the molecular-recognition sites. As expected, the kinetics was found to depend on the average distance over which the adsorbed 2MNQ had to diffuse in order to get to the photocatalytic domains [113]. The same type of molecular recognition SAM (thiolated cyclodextrin) was found to enhance also the photocatalytic degradation of the dye-stuff Chicago Sky Blue 6, which is a long, symmetric molecule whose chemical structure fits the cyclodextrin cavity [51].

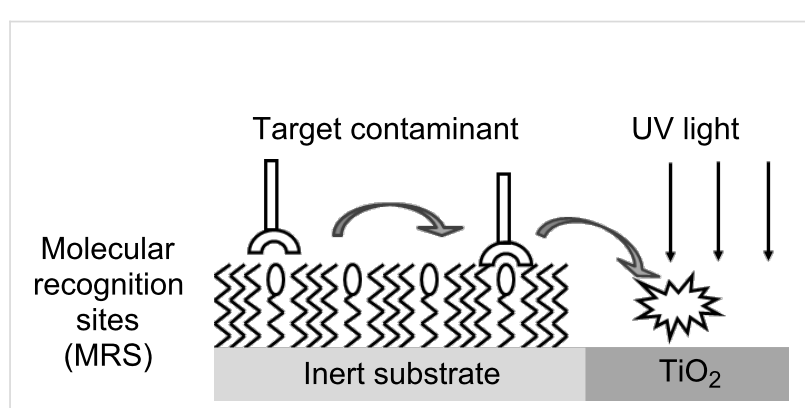

Figure 8: Specific photocatalytic degradation by the "adsorb and shuttle" approach (after [51]).

This so-called "adsorb and shuttle" approach was later implemented also by utilizing $\mathrm{Cu}^{2+}$ ions attached to SAMs of 1,1mercaptoundecanate in order to physisorb diisopropyl methyl phosphonate (DIMP), a known simulant for the nerve gas sarin. Once physisorbed, the DIMP molecules diffused to the $\mathrm{TiO}_{2}$ domains where they were photocatalytically degraded in a mechanism similar to that observed with $\mathrm{TiO}_{2}$ alone, namely, via the formation of acetone as an intermediate product. An enhancement factor of 4-6 relative to bare $\mathrm{TiO}_{2}$ was observed [114].

It is noteworthy that the phenomenon of remote degradation discussed above poses a severe limitation to the concept of selective photocatalysis, as the SAMs might be prone to eventual degradation upon exposure to UV light. Placing the molecular recognition sites on thin films of metals such as gold helps to overcome this problem, as it stabilizes the monolayers against remote degradation, nevertheless this solution might be 
insufficient in powders, where the size of the metallic domains is significantly smaller than the size in the works presented above.

\section{Other applications}

The ability to controllably tailor the properties of SAMs, in combination with the specific properties of titanium dioxide, which include photocatalytic activity and superhydrophilicity, provides a platform for a wide range of applications. Among these, one may highlight the UV-protected polymeric materials based on amorphous $\mathrm{TiO}_{2}$ grown on sulfonated SAMs attached to polymeric sheets [115]. Another application is the use of hydrophobic SAMs $(1 H, 1 H, 2 H, 2 H$-perflurooctyl-triethoxysilane) attached to $\mathrm{TiO}_{2}$ on titanium to improve the blood compatibility of titanium-based biomedical devices and implants [116]. A different application is the prevention of pitting corrosion by the highly uniform films of $\mathrm{TiO}_{2}$ grown on sulfonate-terminated SAMs [117].

\section{Conclusion}

The ability to control the properties of self-assembled monolayers (SAMs) attached to solid surfaces and the unusual photocatalytic properties of titanium dioxide provide a rationale for studying systems comprising of both. Such systems can be realized in the form of SAMs grown on $\mathrm{TiO}_{2}$ or, in a complementary manner, as $\mathrm{TiO}_{2}$ grown on SAMs.

This mini-review summarizes the current knowledge on SAMs attached to titanium dioxide while focusing on the resemblances and differences between SAMs on titania and SAMs on the more frequently studied substrate of silica. Among the differences one finds the use of sulfonic acid headgroups and the faster chemisorption of alkylsilane monolayers.

Mastering micropatterning is a key issue en route to the successful assimilation of a variety of titanium dioxide based devices. Accordingly, particular attention was given to describing a variety of methods and techniques aimed at exploiting the photocatalytic properties of titanium dioxide for patterning. Reports on a variety of applications were discussed. The examples portrayed above, representing the areas of photovoltaics, microelectronics, microelectromechanics, photocatalysis, corrosion prevention and even biomedicine should be regarded as appetizers, paving the way for further studies to be performed.

\section{Acknowledgements}

The assistance of I. Rozen in performing the literature search for this review is gratefully acknowledged. The author also thanks the Russell Berrie Institute of Nanotechnology and the Grand Water Research Institute for their support.

\section{References}

1. Blake, D. M. Bibliography of Work on the Photocatalytic Removal of Hazardous Compounds from Water and Air; National Renewable Energy Laboratory: Golden, Colorado, 1994.

2. Halman, M. M. Photodegradation of water pollutants; CRC Press: Boca Raton, 1996.

3. Paz, Y.; Luo, Z.; Rabenberg, L.; Heller, A. J. Mater. Res. 1995, 10, 2842-2848.

4. Gerischer, H.; Heller, A. J. Phys. Chem. 1991, 95, 5261-5267. doi:10.1021/j100166a063

5. Hoffmann, M. R.; Martin, S. T.; Choi, W.; Bahnemann, D. W. Chem. Rev. 1995, 95, 69-96. doi:10.1021/cr00033a004

6. Paz, Y. Solid State Phenom. 2010, 162, 135-162. doi:10.4028/www.scientific.net/SSP.162.135

7. Bahnemann, D. W.; Moeing, J.; Chapman, R. J. Phys. Chem. 1987, 91, 3782-3788. doi:10.1021/j100298a014

8. Cho, Y.; Choi, W.; Lee, C.-H.; Hyeon, T.; Lee, H.-I. Environ. Sci. Technol. 2001, 35, 966-970. doi:10.1021/es001245e

9. Shaham Waldmann, N.; Paz, Y. J. Phys. Chem. C 2010, 114, 18946-18952. doi:10.1021/jp105925g

10. Muñoz, J.; Domènech, X. J. Appl. Electrochem. 1990, 20, 518-521. doi:10.1007/BF01076066

11. Turchi, C. S.; Ollis, D. F. J. Catal. 1990, 122, 178-192. doi:10.1016/0021-9517(90)90269-P

12. Minero, C. Catal. Today 1999, 54, 205-216. doi:10.1016/S0920-5861(99)00183-2

13. Fujishima, A.; Rao, T. N.; Tryk, D. A. J. Photochem. Photobiol., C: Photochem. Rev. 2000, 1, 1-21. doi:10.1016/S1389-5567(00)00002-2

14. Li, J.; Zhu, L.; Wu, Y.; Harima, Y.; Zhang, A.; Tang, H. Polymer 2006, 47, 7361-7367. doi:10.1016/j.polymer.2006.08.059

15. Helmy, R.; Fadeev, A. Y. Langmuir 2002, 18, 8924-8928. doi:10.1021/la0262506

16. Lee, J. P.; Kim, H. K.; Park, C. R.; Park, G.; Kwak, H. T.; Koo, S. M.; Sung, M. M. J. Phys. Chem. B 2003, 107, 8997-9002. doi:10.1021/jp030077k

17. Mattigod, S. V.; Fryxell, G. E.; Alford, K.; Gilmore, T.; Parker, K.; Serne, J.; Engelhard, M. Environ. Sci. Technol. 2005, 39, 7306-7310. doi:10.1021/es048982I

18. Haick, H.; Sagatelian, Y.; Paz, Y. Langmuir 2003, 19, 2540-2544. doi:10.1021/la020452k

19. Kim, W.-J.; Kim, S.; Lee, B. S.; Kim, A.; Ah, C. S.; Huh, C.; Sung, G. Y.; Yun, W. S. Langmuir 2009, 25, 11692-11697. doi:10.1021/la901615e

20. Brunner, H.; Vallant, T.; Mayer, U.; Hoffmann, H.; Basnar, B.; Vallant, M.; Friedbacher, G. Langmuir 1999, 15, 1899-1901. doi:10.1021/la981426i

21. Cohen, S. R.; Naaman, R.; Sagiv, J. J. Phys. Chem. 1986, 90, 3054-3056. doi:10.1021/j100405a004

22. Shin, H.; Wang, Y.; Sampathkumaran, U.; De Guire, M. R.; Heuer, A. H.; Sukenik, C. N. J. Mater. Res. 1999, 14, 2116-2123. doi:10.1557/JMR.1999.0286

23. Hozumi, A.; Cheng, D. F.; Yagihashi, M. J. Colloid Interface Sci. 2011, 353, 582-587. doi:10.1016/j.jcis.2010.09.075

24. Loste, E.; Fraile, J.; Fanovich, M. A.; Woerlee, G. F.; Domingo, C. Adv. Mater. 2004, 16, 739-744. doi:10.1002/adma.200306214

25. García-González, C. A.; Saurina, J.; Ayllón, J. A.; Domingo, C. J. Phys. Chem. C 2009, 113, 13780-13786. doi:10.1021/jp9029985

26. Marcinko, S.; Helmy, R.; Fadeev, A. Y. Langmuir 2003, 19, 2752-2755. doi:10.1021/la026620q 
27. Hofer, R.; Textor, M.; Spencer, N. D. Langmuir 2001, 17, 4014-4020. doi:10.1021/la001756e

28. Liu, H.-B.; Venkataraman, N. V.; Spencer, N. D.; Textor, M.; Xiao, S.-J. ChemPhysChem 2008, 9, 1979-1981. doi:10.1002/cphc.200800381

29. Brodard-Sevarac, F.; Guerrero, G.; Maquet, J.; Florian, P.; Gervais, C.; Mutin, P. H. Chem. Mater. 2008, 20, 5191-5196. doi:10.1021/cm8012683

30. Chen, Y.; Liu, W.; Ye, C.; Yu, L.; Qi, S. Mater. Res. Bull. 2001, 36, 2605-2612. doi:10.1016/S0025-5408(01)00731-0

31. Pan, D.; Xu, G.; Wan, J.; Shi, Z.; Han, M.; Wang, G. Langmuir 2006, 22, 5537-5540. doi:10.1021/la060401d

32. Hozumi, A.; Kim, B.; McCarthy, T. J. Langmuir 2009, 25, 2875-2880. doi:10.1021/la803564c

33. Shin, H.; Collins, R. J.; De-Guire, M. R.; Heuer, A. H.; Sukenik, C. N J. Mater. Res. 1995, 10, 692-698.

34. Liang, S.; Chen, M.; Xue, Q. Colloids Surf., A 2008, 324, 137-142. doi:10.1016/j.colsurfa.2008.04.032

35. Xiao, Z.; Gu, J.; Huang, D.; Lu, Z.; Wei, Y. Appl. Surf. Sci. 1998, 125, 85-92. doi:10.1016/S0169-4332(97)00388-7

36. Xiao, Z.; Su, L.; Gu, N.; Lu, Z.; Wei, Y. Thin Solid Films 1998, 333, 25-28. doi:10.1016/S0040-6090(98)00760-3

37. Pizem, H.; Sukenik, C. N.; Sampathkumaran, U.; Mcllwain, A. K.; De Guire, M. R. Chem. Mater. 2002, 14, 2476-2485. doi:10.1021/cm010776e

38. Masuda, Y.; Sugiyama, T.; Seo, W. S.; Koumoto, K. Chem. Mater. 2003, 15, 2469-2476. doi:10.1021/cm030255m

39. Desu, S. B. Mater. Sci. Eng., B 1992, 13, 299-303. doi:10.1016/0921-5107(92)90132-S

40. Yamabi, S.; Imai, H. Thin Solid Films 2003, 434, 86-93. doi:10.1016/S0040-6090(03)00539-X

41. Xiang, J.; Zhu, P.; Masuda, Y.; Koumoto, K. Langmuir 2004, 20 , 3278-3283. doi:10.1021/la036088m

42. Lin, H.; Kozuka, H.; Yoko, T. Mol. Cryst. Liq. Cryst. 1999, 337, 217-220. doi:10.1080/10587259908023416

43. Lin, H.; Kozuka, H.; Yoko, T. Thin Solid Films 1998, 315, 111-117. doi:10.1016/S0040-6090(97)00759-1

44. Shin, H.; Collins, R. J.; De-Guire, M. R.; Heuer, A. H.; Sukenik, C. N. J. Mater. Res. 1995, 10, 699-703.

45. Rizza, R.; Fitzmaurice, D.; Hearne, S.; Hughes, G.; Spoto, G.; Ciliberto, E.; Kerp, H.; Schropp, R. Chem. Mater. 1997, 9, 2969-2982. doi:10.1021/cm970349u

46. Shimizu, Y.; Kawanabe, K.; Takao, Y.; Egashira, M. J. Am. Ceram. Soc. 2001, 84, 301-306. doi:10.1111/j.1151-2916.2001.tb00654.x

47. Lee, J. P.; Jang, Y. J.; Sung, M. M. Adv. Funct. Mater. 2003, 13, 873-876. doi:10.1002/adfm.200304445

48. Seo, E. K.; Lee, J. W.; Sung-Suh, H. M.; Sung, M. M. Chem. Mater. 2004, 16, 1878-1883. doi:10.1021/cm035140x

49. Haick, H.; Paz, Y. J. Phys. Chem. B 2001, 105, 3045-3051. doi:10.1021/jp0037807

50. Zemel, E.; Paz, Y. J. Adv. Oxid. Technol. 2002, 5, 27-32.

51. Ghosh-Mukerji, S.; Haick, H.; Paz, Y. J. Photochem. Photobiol., A: Chem. 2003, 160, 77-85. doi:10.1016/S1010-6030(03)00224-7

52. Shemer, G.; Paz, Y. Int. J. Photoenergy 2011, No. 596710. doi:10.1155/2011/596710

53. Haick, H.; Paz, Y. J. Phys. Chem. B 2003, 107, 2319-2326. doi:10.1021/jp026940i
54. Howgate, J.; Schoell, S. J.; Hoeb, M.; Steins, W.; Baur, B.; Hertrich, S.; Nickel, B.; Sharp, I. D.; Stutzmann, M.; Eickhoff, M. Adv. Mater. 2010, 22, 2632-2636. doi:10.1002/adma.200903756

55. Tizazu, G.; Adawi, A. M.; Leggett, G. J.; Lidzey, D. G. Langmuir 2009 , 25, 10746-10753. doi:10.1021/la901271c

56. Jeon, N. L.; Nuzzo, R. G.; Xia, Y.; Mrksich, M.; Whitesides, G. M. Langmuir 1995, 11, 3024-3026. doi:10.1021/la00008a029

57. Xia, Y.; Whitesides, G. M. Angew. Chem., Int. Ed. 1998, 37, 550-575. doi:10.1002/(SICI)1521-3773(19980316)37:5<550::AID-ANIE550>3.0. CO;2-G

58. Denis, F. A.; Hanarp, P.; Sutherland, D. S.; Dufrêne, Y. F. Langmuir 2004, 20, 9335-9339. doi:10.1021/la049188g

59. Ye, T.; Wynn, D.; Dudek, R.; Borguet, E. Langmuir 2001, 17, 4497-4500. doi:10.1021/la010697h

60. Nakata, K.; Nishimoto, S.; Yuda, Y.; Ochiai, T.; Murakami, T.; Fujishima, A. Langmuir 2010, 26, 11628-11630. doi:10.1021/la101947y

61. Nishimoto, S.; Kubo, A.; Zhang, X.; Liu, Z.; Taneichi, N.; Okui, T.; Murakami, T.; Komine, T.; Fujishima, A. Appl. Surf. Sci. 2008, 254, 5891-5894. doi:10.1016/j.apsusc.2008.03.153

62. Nishimoto, S.; Sekine, H.; Zhang, X.; Liu, Z.; Nakata, K.; Murakami, T.; Koide, Y.; Fujishima, A. Langmuir 2009, 25, 7226-7228. doi:10.1021/la9011372

63. Lee, J. P.; Sung, M. M. J. Am. Chem. Soc. 2004, 126, 28-29. doi:10.1021/ja038769+

64. Notsu, H.; Kubo, W.; Shitanda, I.; Tatsuma, T. J. Mater. Chem. 2005, 15, 1523-1527. doi:10.1039/b418884e

65. Blondiaux, N.; Zürcher, S.; Liley, M.; Spencer, N. D. Langmuir 2007, 23, 3489-3494. doi:10.1021/la063186+

66. Bai, Y.; Zhang, Y.; Li, W.; Zhou, X.; Wang, C.; Feng, X.; Zhang, L.; Lu, X. Appl. Surf. Sci. 2009, 255, 9296-9300. doi:10.1016/j.apsusc.2009.06.115

67. Haick, H.; Paz, Y. ChemPhysChem 2003, 4, 617-620. doi:10.1002/cphc.200200622

68. Kwon, B. G.; Kwon, J.-H. J. Ind. Eng. Chem. 2010, 16, 193-199. doi:10.1016/j.jiec.2009.10.007

69. Masuda, Y.; Gao, Y.; Zhu, P.; Shirahata, N.; Saito, N.; Koumoto, K. J. Ceram. Soc. Jpn. 2004, 112, S1495-S1505.

70. Masuda, Y.; Kondo, M.; Koumoto, K. Cryst. Growth Des. 2009, 9 , 555-561. doi:10.1021/cg800856m

71. Masuda, Y.; Sugiyama, T.; Lin, H.; Seo, W. S.; Koumoto, K. Thin Solid Films 2001, 382, 153-157. doi:10.1016/S0040-6090(00)01761-2

72. Masuda, Y.; Seo, W. S.; Koumoto, K. Langmuir 2001, 17, 4876-4880. doi:10.1021/la0014609

73. Masuda, Y.; Jinbo, Y.; Yonezawa, T.; Koumoto, K. Chem. Mater. 2002, 14, 1236-1241. doi:10.1021/cm0107528

74. Koumoto, K.; Seo, S.; Sugiyama, T.; Seo, W. S.; Dressick, W. J. Chem. Mater. 1999, 11, 2305-2309. doi:10.1021/cm990223s

75. Masuda, Y.; Saito, N.; Hoffmann, R.; De Guire, M. R.; Koumoto, K. Sci. Technol. Adv. Mater. 2003, 4, 461-467. doi:10.1016/j.stam.2003.08.002

76. Xiang, J.; Masuda, Y.; Koumoto, K. Adv. Mater. 2004, 16, 1461-1464. doi:10.1002/adma.200400017

77. Masuda, Y.; Sugiyama, T.; Koumoto, K. J. Mater. Chem. 2002, 12, 2643-2647. doi:10.1039/b203786f

78. Collins, R. J.; Shin, H.; De Guire, M. R.; Heuer, A. H.; Sukenik, C. N Appl. Phys. Lett. 1996, 69, 860-862. doi:10.1063/1.117916

79. Park, M. H.; Jang, Y. J.; Sung-Suh, H. M.; Sung, M. M. Langmuir 2004, 20, 2257-2260. doi:10.1021/la035760c 
80. Cherniavskaya, O.; Adzic, A.; Knutson, C.; Gross, B. J.; Zang, L.; Liu, R.; Adams, D. M. Langmuir 2002, 18, 7029-7034. doi:10.1021/la0114575

81. Shin, H.; Jeong, D.-K.; Lee, J.; Sung, M. M.; Kim, J. Adv. Mater. 2004, 16, 1197-1200. doi:10.1002/adma.200306296

82. Bae, C.; Shin, H.; Moon, J.; Sung, M. M. Chem. Mater. 2006, 18, 1085-1088. doi:10.1021/cm052084m

83. Masuda, Y.; Seo, W.-S.; Koumoto, K. Solid State lonics 2004, 172, 283-288. doi:10.1016/j.ssi.2004.02.068

84. Lai, Y.; Huang, J.; Gong, J.; Huang, Y.; Wang, C.; Chen, Z.; Lin, C. J. Electrochem. Soc. 2009, 156, D480-D484. doi:10.1149/1.3216032

85. O'Regan, B.; Grätzel, M. Nature 1991, 353, 737-740. doi:10.1038/353737a0

86. Kamat, P. V.; Gevaert, M.; Vinodgopal, K. J. Phys. Chem. B 1997, 101, 4422-4427. doi:10.1021/jp970047f

87. Shi, Z.; Li, Y.; Wang, S.; Guo, Z.; Du, C.; Xiao, S.; Sun, N.; Cao, Y.; Yao, J.; Zhu, D.; Gao, E.; Cai, S. Chem. Phys. Lett. 2001, 336, 19-23. doi:10.1016/S0009-2614(01)00071-9

88. Chong, S. V.; Suresh, N.; Xia, J.; Al-Salim, N.; Idriss, H. J. Phys. Chem. C 2007, 111, 10389-10393. doi:10.1021/jp072579u

89. Pan, J.; Xu, Y.; Sun, L.; Sundström, V.; Polívka, T. J. Am. Chem. Soc. 2004, 126, 3066-3067. doi:10.1021/ja031775I

90. Haubner, K.; Jaehne, E.; Adler, H.-J. P.; Koehler, D.; Loppacher, C.; Eng, L. M.; Grezner, J.; Herasimovich, A.; Scheinert, S. Phys. Status Solidi A 2008, 205, 430-439. doi:10.1002/pssa.200723407

91. Gilmer, D. C.; Colombo, D. G.; Taylor, C. J.; Roberts, J.; Haugstad, G.; Campbell, S. A.; Kim, H.-S.; Wilk, G. D.; Gribelyuk, M. A.; Gladfelter, W. L. Chem. Vap. Deposition 1998, 4, 9-11. doi:10.1002/(SICI)1521-3862(199801)04:01<9::AID-CVDE9>3.3.CO;2 $-\mathrm{V}$

92. Gao, Y.; Masuda, Y.; Koumoto, K. Chem. Mater. 2004, 16, 1062-1067. doi:10.1021/cm030543i

93. Koumoto, K.; Masuda, Y.; Wang, D. J. Int. J. Soc. Mater. Eng. Resour. 2002, 10, 49-52.

94. Campbell, S. A.; Gilmer, D. C.; Wang, X.-C.; Hsieh, M.-T.; Kim, H.-S.; Gladfelter, W. L.; Yan, J. IEEE Trans. Electron Devices 1997, 44, 104-109. doi:10.1109/16.554800

95. Shin, H.; De Guire, M. R.; Heuer, A. H. J. Appl. Phys. 1998, 83, 3311-3317. doi:10.1063/1.367132

96. Shyue, J.-J.; Padture, N. P. Mater. Lett. 2007, 61, 182-185. doi:10.1016/j.matlet.2006.04.100

97. Majewski, L. A.; Schroeder, R.; Grell, M. Adv. Funct. Mater. 2005, 15, 1017-1022. doi:10.1002/adfm.200400570

98. Avnon, E.; Paz, Y.; Tessler, N. Appl. Phys. Lett. 2009, 94, 013502. doi:10.1063/1.3064158

99. Ashurst, W. R.; Jang, Y. J.; Magagnin, L.; Carraro, C.; Sung, M. M.; Maboudian, R. Nanometer-thin titania films with SAM-level stiction and superior wear resistance for reliable MEMS performance. IEEE International Conference on Micro Electro Mechanical Systems, Maastricht, The Netherlands, Jan 25-29, 2004; pp 153-156. doi:10.1109/MEMS.2004.1290545

100.Senadeera, G. K. R.; Kitamura, T.; Wada, Y.; Yanagida, S. J. Photochem. Photobiol., A: Chem. 2004, 164, 61-66. doi:10.1016/j.jphotochem.2003.12.026

101.Senadeera, G. K. R.; Kitamura, T.; Wada, Y.; Yanagida, S. J. Photochem. Photobiol., A: Chem. 2006, 184, 234-239. doi:10.1016/j.jphotochem.2006.04.033
102. Hau, S. K.; Yip, H.-L.; Acton, O.; Baek, N. S.; Ma, H.; Jen, A. K.-Y. J. Mater. Chem. 2008, 18, 5113-5119. doi:10.1039/b808004f

103.Hsu, C.-W.; Wang, L.; Su, W.-F. J. Colloid Interface Sci. 2009, 329, 182-187. doi:10.1016/j.jcis.2008.10.008

104.Chong, L.-W.; Chien, H.-T.; Lee, Y.-L. J. Power Sources 2010, 195, 5109-5113. doi:10.1016/j.jpowsour.2010.01.044

105. Jin-nouchi, Y.; Naya, S.-i.; Tada, H. J. Phys. Chem. C 2010, 114, 16837-16842. doi:10.1021/jp1062226

106.Ardalan, P.; Brennan, T. P.; Lee, H.-B.-R.; Bakke, J. R.; Ding, I.-K.; McGehee, M. D.; Bent, S. F. ACS Nano 2011, 5, 1495-1504. doi:10.1021/nn103371v

107.Wang, P.; Zakeeruddin, S. M.; Humphry-Baker, R.; Moser, J. E.; Grätzel, M. Adv. Mater. 2003, 15, 2101-2104. doi:10.1002/adma.200306084

108. Nakata, K.; Nishimoto, S.; Kubo, A.; Tryk, D.; Ochiai, T.; Murakami, T.; Fujishima, A. Chem.-Asian J. 2009, 4, 984-988. doi:10.1002/asia.200900005

109. Nishimoto, S.; Kubo, A.; Nohara, K.; Zhang, X.; Taneichi, N.; Okui, T.; Liu, Z.; Nakata, K.; Sakai, H.; Murakami, T.; Abe, M.; Komine, T.; Fujishima, A. Appl. Surf. Sci. 2009, 255, 6221-6225. doi:10.1016/j.apsusc.2009.01.084

110. Naoi, K.; Ohko, Y.; Tatasuma, T. J. Am. Chem. Soc. 2004, 126, 3664-3668. doi:10.1021/ja039474z

111. Naoi, K.; Ohko, Y.; Tatasuma, T. Chem. Commun. 2005, 1288-1290. doi:10.1039/b416139d

112.Paz, Y. C. R. Chim. 2006, 9, 774-787. doi:10.1016/j.crci.2005.03.032 113. Ghosh-Mukerji, S.; Haick, H.; Schvartzman, M.; Paz, Y. J. Am. Chem. Soc. 2001, 123, 10776-10777. doi:10.1021/ja0117635 114. Sagatelian, Y.; Sharabi, D.; Paz, Y. J. Photochem. Photobiol., A: Chem. 2005, 174, 253-260. doi:10.1016/j.jphotochem.2005.03.021

115.Baskaran, S.; Song, L.; Liu, J.; Chen, Y. L.; Graff, G. L. J. Am. Ceram. Soc. 1998, 81, 401-408. doi:10.1111/j.1151-2916.1998.tb02347.x

116. Yang, Y.; Lai, Y.; Zhang, Q.; Wu, K.; Zhang, L.; Lin, C.; Tang, P. Colloids Surf., B 2010, 79, 309-313. doi:10.1016/j.colsurfb.2010.04.013

117. Meth, S.; Savchenko, N.; Koltypin, M.; Starosvetsky, D.; Viva, F. A.; Groysman, A.; Sukenik, C. N. Corros. Sci. 2010, 52, 125-129. doi:10.1016/j.corsci.2009.08.052

\section{License and Terms}

This is an Open Access article under the terms of the Creative Commons Attribution License (http://creativecommons.org/licenses/by/2.0), which permits unrestricted use, distribution, and reproduction in any medium, provided the original work is properly cited.

The license is subject to the Beilstein Journal of Nanotechnology terms and conditions: (http://www.beilstein-journals.org/bjnano)

The definitive version of this article is the electronic one which can be found at:

doi:10.3762/bjnano.2.94 